\title{
Urban Regeneration and Heritage Preservation with Public Participation: The Case of the Kai Tak Runway in Hong Kong
}

\author{
Claudio O. Delang ${ }^{*}$ and Yan $\mathrm{Ng}$
}

Department of Geography and Resource Management, The Chinese University of Hong Kong, Hong Kong, China

\begin{abstract}
This paper discusses the preservation of heritage in Hong Kong using the case study of the redevelopment of Kai Tak Airport and Runway 13. Kai Tak Airport was closed in 1998, and the Urban Redevelopment Authority launched a series of consultations to give the community the opportunity to participate in the redevelopment of the area. This paper discusses the process of consultation organized by the URA, the proposals advanced by different interest groups, and ultimately the difficulties in bringing together stakeholders with opposing interests, especially with such a contentious issue as a waterfront regeneration project in a highly congested area like the Kowloon area in Hong Kong.
\end{abstract}

\section{INTRODUCTION}

On Tuesday, December 12, 2006, the Central Star Ferry Pier and the Clock Tower were demolished to make way for the Central reclamation project. This incident marked a historical moment for many Hong Kong residents, since the Pier and the Clock tower are widely recognized as part of the local collective memory. In the weeks before the termination of the ferry service from the pier, articles such as 'Save the Star Ferry Pier and the Clock Tower' and 'Goodbye Clock Tower' appeared in the mass media and thousands of emotional local citizens arrived to post banners in support of their retention. The start of demolition work was the signal for more active opposition. As soon as the bell and clock face had been removed from the tower, protestors began to gather at the Star Ferry. Activists rushed into and occupied part of the demolition site, chanting slogans and demanding to meet the Secretary for Housing, Planning and Lands, Mr. Michael Suen Ming Yeung. The initial demonstrations appear to have been spontaneous. However, the spread of news about these demonstrations prompted many more protestors to gather. Various associations, including the Civil Party and the usually pro-government Democratic Alliance for Betterment of Hong Kong also showed up to give their support.

Hong Kong is a liberal city, where freedom and rights are strongly emphasized. Furthermore, in recent urban planning practices, the issue of 'transparency' and the involvement of the community have been integrated into the local planning policies so as to make urban living spaces more 'peopleoriented'. However, in the case of the demolition of the Central Star Ferry Pier and the Clock Tower, what do all these protests and demonstrations imply regarding urban planning practices in Hong Kong? Where do these widespread condemnations come from? And why is that? The public, legislators and conservationists claimed that the actions of the government were contrary to the wishes of the

*Address correspondence to this author at the Department of Geography and Resource Management, The Chinese University of Hong Kong, Hong Kong, China; E-mail: cdelang@cuhk.edu.hk public. The Legislative Council tabled motions to halt to demolition immediately, pending further consultation. However, the government denied a last-minute reprieve, reiterating that there had been an 'adequate consultation', and forged ahead with the demolition. This might raise deeper questions about the preservation of history and heritage in Hong Kong. In the process of development, the growth of a city and the preservation and conservation of local culture and heritage often collide. The rapid development of Hong Kong's economy has raised public expectations for quality living standards, as well as better town planning and a better living environment. These rising expectations have been accompanied by growing concerns over the impact of urban renewal processes in the historical and cultural ambience of older districts in Hong Kong [1]. As Dr. Patrick Ho, Secretary for Home Affairs, said, 'We must seek to suitably preserve built heritage with historical value during the town planning and urban renewal process, through a series of legal and administrative procedures' [1].

While the urban planning process is claimed to be 'transparent', there are conflicts between the government and the public, or between different interest groups. Whenever a new planning project is launched, a series of public forums and consultations, held by government organizations or responsible institutions, aiming at gathering views from the community, will follow. Conflicts will still exist though, because planning is a very complicated process, which involves a wide range of people and organizations with different points of view regarding particular planning issues. Hence, it is a difficult task to generate a plan, which everybody will agree on. Although community members have the opportunity to express their opinion on planning issues, their views might not be utilized or made use of at the end. At the same time, since the decision ultimately lies with the government, the government can launch a series of consultations and ignore the findings, while forging ahead with its original plans, claiming that there has been adequate consultation. So we might ask, how far can the community members exert their influence into planning their neighbourhood? And is the government actually granting rights to the citizen to plan, or is it just a superficial tactic to ease public discontent? 
This paper attempts to investigate further the planning process using the case study of the Hong Kong old airport site, Kai Tak, which is now being redeveloped as a waterfront site. The paper will focus on issues regarding the runway, and exclude the related land to the north. In the research and analysis section, the redevelopment project will not be looked at as a whole integrated and comprehensive plan. Instead, the main focus of this paper will be the preservation of the runway, the proposed plans, and the conflicting interests of different stakeholders. This paper will show the ways in which different stakeholders and interest groups, with a vested interest in the Kai Tak Redevelopment Project, participate, promote, and defend their interests and points of view. The planning process, including the government's efforts to involve the general public so as to improve the 'transparency' of the planning process, will also be discussed. Different proposals about the Kai Tak runway will be analysed, enabling us to address the controversial issues about 'whether to preserve', 'how to preserve' and 'how to make adaptive use of the runway'. With the anticipated conflicting interests of the different community groups, it is hoped that the results of this paper will give an idea about how complicated and contradictory a redevelopment planning process is. The case of Kai Tak in Hong Kong will be used in this paper to examine key issues regarding a waterfront regeneration process. In particular, the following questions will be addressed: - Who are the main actors and participants in this waterfront regeneration project in terms of the runway preservation/ land use aspect? - What are their respective views regarding the preservation and use of the runway? - What are the agendas and motives behind the proposed plans?

This study will illustrate how the regeneration process is influenced by local politics and the interests and powers of different groups, and will shed light on the role of the government and the planning authorities in the resulting process. It will also identify the conflicts between different interest parties and demonstrate the complexity of the urban planning process.

\section{URBAN PLANNING AND HERITAGE PRESER- VATION IN HONG KONG}

Veal [2] stated that 'planning can be seen as the process of deciding'. However, the regeneration planning process is not just about 'deciding' what is to be provided in the future, especially when elements of tourism are to be included. It is much more complex. Chadwick's [3] response to 'what is planning' is more relevant. Chadwick states that 'planning is a process, a process of human thought and action based upon that thought - in point of fact, forethought, thought for the future - nothing more or less than this is planning, which is a very general human activity' (p. 24). Hall's explanation of what is planning should further support Chadwick's case: planning 'should aim to provide a resource for democratic and informed decision-making. This is all planning can legitimately do, and all it can pretend to do. Properly understood, this is the real message of the systems revolution in planning and its aftermath' [4]. Therefore, planning is actually a component of an overall 'planning-decisionaction' process. Further, various activities in that process may be difficult to isolate, as the planning process involves bargaining and negotiation, compromise, coercion, interests, values, choice, and of course, politics [5].

The focus of this paper is on the planning process itself, and we will see whether the above-mentioned processes are also relevant to the selected case study. According to Hall [6], the dominant approach to planning within the private sector is that of boosterism, while the attention of the government to the potential economic benefits has also provided a major driving force for planning. In the 'growth machine' model pioneered by Logan and Molotch [7], urban development in the context of the US political economy is seen as a process in which major interest groups such as property rentiers, developers, financiers, public utilities, politicians, pro-growth associations and government bodies form a coalition to drive the urban 'growth machine' to capture the exchange-value of the city property, maximize economic gains from their assets, and benefit their own fortune building [8]. In this model, development is regarded as the overarching aim of municipal affairs, and urban politics is identified as being dominated if not determined by the need for economic growth. In a similar manner but a broader perspective, the urban regime theory emphasizes the significance of partnerships or coalitions, formed on the basis of mutual self-interest between governmental and nongovernmental actors across institutional lines, in order to produce a capacity to govern and to bring about publicly significant results.

In an analysis of urban development in Atlanta, Georgia, over a period of 40 years, Stone states the stability and continuity of urban governance in terms of the persistence of the coalition of business and politics around development, in spite of the frequent coming and going of mayors with varied ideas and bases of electoral support [8]. The result has often been 'top-down planning and promotion that leaves destination communities with little input or control over their own destinies' [9]. However, attention is gradually focusing on the need to integrate social and environmental concerns into the economic thrust of development [6]. Getz [10] understandably defines planning as a process, based on research and evaluation, which seeks to optimise the potential contribution of urban development to human welfare and environmental quality. Similarly, Murphy [9] observes that "planning is concerned with anticipating and regulating change in a system, to promote orderly development so as to increase the social, economic, and environmental benefits of the development process' (p.156).

The approaches of Murphy [9] and Getz [10], as well as those of Gunn [11] and Inskeep [12], are based on prescriptive models of planning as a basis for public participation within a community. Prescriptive models serve as a guide to an ideal situation. However, while these may be useful rational models against which to compare reality, they do not provide detailed insights into the real world of planning and its associated set of values, power and interests. As stated by Tyler et al. [13], many discussions of the opportunities for community participation in the planning processes might appear to be overly optimistic. This paper attempts to argue against an idealized representations of the opportunities for community participation in the planning processes, using the case study of Kai Tak in Hong Kong, 
which shows the difficulties of 'bottom-top' planning policies.

An example of top-down v. bottom up planning policies is that of Darling Harbour in Sydney, where the state government controlled redevelopment projects, despite the wishes of the City Council and the opinions from the public. The content of these schemes was an expression of how the state government was determined to think globally about the city's economy, while the City Council continued to be concerned with political in-fighting and the needs of residents rather than those of business [14]. In describing the redevelopment of the inner harbour in Baltimore, Harvey [15] commented: 'The present carnival mask of the Inner Harbour redevelopment conceals the long history of struggle over this space... The inner city space became a space of conspicuous consumption, celebrating commodities rather than civic values.' (p. 421-422) The new inner-city space of leisure consumption, the city as fun and spectacle, is reflective not just of particular values but also of particular interests. As Hall and Jenkins [5] stated, values and interests are inextricably linked, the 'new' civic values reflecting those of the local elites which influence urban redevelopment and planning processes. As Mommaas and van der Poel [16] observed, 'local policy has increasingly sought to stimulate the mixture of economic enterprise, culture and leisure, attempting in this manner to attract a new economic elite to the city' (p. 267). However, it tends to focus on one set of economic and social interests other than community interests, especially those of traditional innercity residents of lower socio-economic status, which are increasingly being neglected. One key element of the planning process we might want to look at is equality and access to power $[6,17]$.

The study of planning needs to seek ways in which community power structures can be better understood so as to maximize input into planning processes and the design of better procedures. As Hall [17] suggested, concerns over networks and partnerships need to go beyond simplistic discussions of public-private partnerships to ones that include the wider community. Furthermore, greater attention needs to be given to the role of persuasion and argument as a planning tool. Although public involvement might not be recognized as a substantial element in the redevelopment projects in countries such as Australia, the final development has been a resounding success. Darling Harbour has become famous for its successful transformation from an obsolete stretch of dockyards into a leisure and recreational destination of international calibre.

In the next section, we address the planning practices of Hong Kong, using Kai Tak as a case study. However, before discussing the situation of Kai Tak, we introduce the issue of urban waterfront regeneration - 'urban waterfront' means the water's edge in cities and towns of all sizes. The water could be a river, lake, ocean, bay, creek or canal - how the concept has evolved over time, and the type of governance and policies adopted for waterfront regeneration projects. Kai Tak is the last major undeveloped site around Victoria Harbour, and its renewal is being treated as a waterfront regeneration project. Not only is 'planning' as a whole a complicated process, but a narrower scope - waterfront regeneration - could be even more complicated since the competition for waterfront space is keen in urban cities and public access to the waterfront is much emphasized.

\section{WATERFRONT REGENERATION}

A harbour is always regarded as a valuable asset for a city. Commercial, industrial and tourism-oriented activities tend to cluster around a harbour. The role of harbours has evolved over time. A century ago, sites with good sea or river access were most likely to be chosen for founding cities because they facilitated industrial development. The urban waterfront was thus taken over by giant ports and uses such as warehouses, factories and transportation. For example, Darling Harbour (in Sydney) used to be an industrial port.

In recent decades the attraction of the urban coastlines has been recognized and efforts have been made to preserve what is left of them [18]. The waterfronts are often strategic areas, because their usage has both direct and indirect impacts on the image of the place and on social equity (for example issues regarding gentrification), and at the same time they quite often represent non-built natural resources or green areas in the urban structure [18]. Since the 1970s, numerous waterfronts have undergone a reorientation from 'brown fields' or 'green belts' to commercial, residential and recreational areas. As a consequence, new laws and planning tools have emerged to regulate what can be built near the water. In coastal urban areas, the competition for waterfront space, the importance for public access to the shore and the conservation of waterfront biodiversity as a natural resource, have become an increasingly topical issue in urban policy [19]. It is said that contemporary urban waterfront redevelopment and regeneration projects represent today an international undertaking in urban planning and politics [20]. However, this issue is complex, contradictory, and full of pressures, based on different actors and their respective views.

The varied physical context and multiplicity of needs make urban waterfront design both a challenge and an opportunity [18]. Urban waterfronts always tend to attract proposals for regeneration and revitalization, either to achieve a city's economic goals or to improve the quality of life of its citizens. The selected case study - Kai Tak Regeneration - is anticipated to achieve these goals as well. The regeneration is expected to create a vibrant and quality urban life to the local citizens.

Urban waterfront redevelopment today embodies the historical alteration of land and water uses along the coasts of thousands of cities throughout the world. Waterfront 'projects' or 'plans' span everything from a wildlife sanctuary to a container port and the full spectrum of uses between them. A project can be planned as a unified undertaking, or it can be a haphazard development occurring over time, with multiple owners and participants. In a waterfront project, elements ranging from buildings and areas that are not directly on the water but are tied to it visually, historically or ecologically, will be taken into account [18].

Complex and multifaceted, current waterfront redevelopment trends are attributable to a number of factors, notably: (1) Technological changes post World War II, which led to abandonment and/or deterioration of thousands of acres of industrial land across waterfronts, (2) The 
historical preservation movement, (3) Heightened environmental awareness and water cleanup, (4) Consistent pressure to redevelop central city areas, (5) Public (national, provincial and municipal) urban renewal and related assistance [18]. These and other possible forces combined have brought about dramatic changes in the last 30 years that have altered the face of urban waterfronts for present and future generations. The shift from industrial uses of urban waterfronts is as profound as the initial development of harbours and shores for industry, and their use in earlier times for shipping, storage and shipbuilding [18]. During the past decades, various policy concepts have been used in order to govern the structural changes in urban land-use and urban waterfronts. Roberts [21] distinguished five different periods in the evolution of urban regeneration: a) reconstruction $(1950 \mathrm{~s}), \mathrm{b})$ revitalizations $(1960 \mathrm{~s}), \mathrm{c})$ renewal (1970s), d) redevelopment (1980s), e) regeneration (1990s). Urban regeneration has changed from physically oriented sectoral renewal schemes towards a more comprehensive form of policy and practice with more emphasis on integrated treatment. The ideas of it have meant an introduction of broader idea of environmental sustainability, containing also the social dimension and community targets [18].

Urban waterfront policies have evolved over various regeneration periods. Today, urban waterfront regeneration takes place in a social environment of increased capital mobility and inter-urban competition [22]. Because cities have to compete for investments and affluent residents, city governments cannot merely manage the development, i.e. focus on the redistribution of resources, but have to actively pursue investments and publicity to survive in the severe inter-urban competition. Thus, the new configurations are accompanied by more flexible, fragmented and entrepreneurial forms of governance [20]. Urban governance has expanded to include a wide range of private and semipublic actors besides the concerned government bodies. This form of governance, based on public-private partnership, flagship projects, aggressive marketing and consumptionoriented objects such as retail and tourism centres, has been labelled entrepreneurial governance [23], and is often exemplified by large-scale urban waterfront regeneration projects. One of the leading policy strategies of growing cities is densification, i.e. increase of the density of the urban structure in order to advance sustainable development by minimizing investments in infrastructure, energy consumption and emissions from private car traffic [24]. These urban densification processes have intensified the planning and building of waterfront areas near the city centres. Thus, these compaction strategies have led to environmental arguments to 'redevelop' these sensitive areas, which were traditionally difficult and contradictory for policy makers [18].

The role and importance of public involvement in the planning process vary from one country to another. In some countries, the government plays the dominant role to determine what kind of development is to be carried out, and destination communities are given little input or control over their own destinies. In other countries, the development components are subject to the decision of private agencies/ stakeholders while some developments is generated through private-public partnerships. Hong Kong can be considered to be in the latter category. Since public accountability is emphasized in Hong Kong's planning policy, we see various stakeholders taking part in the redevelopment projects, including that of Kai Tak.

\section{HERITAGE PRESERVATION IN HONG KONG}

Although human activity in Hong Kong goes back several thousands of years, Hong Kong was not a densely inhabited island until it was settled by the British in 1842 . Nearly all the city's built heritage dates from the colonial period (1842-1997), and throughout Hong Kong, there are numerous splendid historical buildings demonstrating traditional Chinese, Asian, Western and mixed architectural styles. This reflects Hong Kong's extensive exposure to influences from the rest of the world. The Antiquities and Monuments Ordinance, Cap. 53, commenced operation in 1976 to provide the legal basis for the declaration of monuments. In the same year, the Antiquities Advisory Board and the Antiquities and Monuments Office were established to serve as the advisory body and executive unit respectively to enforce the Ordinance [25]. At the policy level, the Home Affairs Bureau is the authority responsible for overseeing heritage policies and strategies. It cooperates with its executive department, the Leisure and Cultural Services Department, and in particular the Antiquities and Monuments Office to monitor the preservation of cultural heritage and promote heritage education. The protection of the local cultural heritage had not been a priority in policy making, but its significance has increased in recent years. In its 1999 Policy Address, the Chief Executive announced that the Government would review the existing preservation policy and related legislation to improve the protection of historic buildings and archaeological sites [25]. The importance of heritage preservation was further acknowledged by Secretary for Home Affairs Dr Patrick Ho, as he gave his address on Letter to Hong Kong on September 17, 2006,

\begin{abstract}
'When we look for evidence of those generations that passed this way before us, we look for their enduring traces. From the Pyramids of the Nile to the Parthenon of Athens, from the spires of Angkor Wat to the Dunhuang Cave of China, history has assembled for us, over thousands of years, a lasting testament to our life on this planet' [1].
\end{abstract}

He also realized that local heritage 'stands to reason that the best of our achievements should be preserved and cherished, as lasting contributions to the record of who we are and what we have accomplished' [1]. While the city's rapid economic development is inevitable, the preservation of its heritage could serve as a unique and valuable perspective of our personal living space, as it helps to enhance the richness and diversity of urban life.

Over the last 160 years, when Hong Kong was established as an international entrepôt for China trade, the city has undergone a virtually complete transformation. In their haste to grow and expand, in their impatience to become famous and rich, the inhabitants were 'in the habit of buildings and rebuilding, tearing down and replacing' [1]. Preservation was not at the high end of their priorities. However, this is slowly changing now, as there is increasing 
awareness of the losses, or 'a dawning realisation of what they have already sacrificed in the course of our relatively brief and meteoric, but nonetheless astonishingly crowded and impetuous progress' [1]. As Hong Kong people look around them, they can see they have successfully built a metropolis - one of the most distinctive in the world however sadly one that lacks appropriate anchorage in history. Where other, older cities have added new layers of foundation over the past centuries, to become virtual living museums to their enduring psyche, Hong Kong has retained much less of its origins. Fortunately, increasing concern for the environment has led to increasing concern for the local heritage, so that Hong Kong citizens are now more than ever conscious of the principles of preservation. There is an increased realisation of how important it is to preserve the continuity of their community and their culture. This continuity allows them to retain both knowledge and memory, which contributes to their sense of belonging.

This growing public awareness of the significance of heritage preservation has led to joint action by the government and the community to preserve their built heritage [1]. Not only is the community supporting local heritage preservation. They are even turning their verbal support into real life actions. In 2003, the Lui family donated the 70-year-old private residence, Lui Seng Chun, to the government for preservation, and in 2004 the government negotiated with the then proprietor of Kom Tong Hall, a historical mansion built in 1914, which was eventually converted into the Dr. Sun Yat-sen Museum [1]. 'The significance of such donations does not lie in the economic value of the properties concerned, but in public acceptance of heritage preservation as a universal value.' - [1]. Thus, both the community and the government have been gradually acknowledging the importance of preserving the local heritage.

The government has adopted an open-minded approach towards to future development of the preservation of heritage in Hong Kong. We can see this from the recent debates about the preservation of the Central Police Station and Victoria Prison. After officiating at Victoria Prison's open day, Secretary for Economic Development \& Labour Stephen Ip said, 'It is most important for us to listen to the views of the public, the District Council and all the concerned organizations. That is why we welcome activities like the one today.' And that 'It is a good opportunity for the public to come to experience for themselves the present condition of these historic buildings. We welcome their views on the future use of all these buildings' [1].

The uniqueness of Hong Kong's culture lies in our successful blend of East and West, and the newfound resolve to protect Hong Kong's historic heritage must give proper balance and priority to what is selected to be preserved. As defined by the Dr Patrick Ho [1], Hong Kong people have to give due regard to the following fundamental principles: Firstly, to preserve but not to take over ownership; Secondly, to ensure preservation is based on heritage value, and not simply on the age of a building; Thirdly, to strike a proper balance between preservation needs and economic cost; and, Fourthly, to give due regard to private property rights. While considering development plans that involve historical building/ feature, the prime concern should always be how to properly retain the cultural characteristics of the relevant structures. Upon preservation, their innovative and sustainable adaptive re-use, taking account of whether the overall development is compatible with the uniqueness of the building, should also be carefully considered.

\begin{abstract}
'Love and care for old relics and buildings does not arise merely from personal interest in nostalgia. It also testifies to the efforts of Hong Kong people in tracing their own roots through their history and memories, and in building up their cultural identity.' [1]
\end{abstract}

\section{THE URBAN RENEWAL AUTHORITY}

The Urban Renewal Authority is a government organization responsible for carrying out redevelopment projects in Hong Kong. The mission of this authority is 'to create quality and vibrant urban living in Hong Kong - a better home in a world-class city' [26]. To enable a holistic approach to unlock the full potential of urban renewal, the 4Rs strategy is commonly adopted in the planning process. The 4Rs refer to Redevelopment, Rehabilitation, pReservation and Revitalization [26]:

- to accelerate redevelopment by replacing old buildings with new to provide a better living environment and neighbourhood;

- to enable and encourage the rehabilitation of dilapidated buildings to prevent urban decay;

- $\quad$ to preserve by maintaining and restoring buildings of historical and architectural value, and to sustain local characteristics;

- to revitalize through enhancing and strengthening the socio-economic and environmental fabric for the benefit of our urban communities [26].

In planning redevelopment projects, the Urban Renewal Authority works with the government, development and financial institutions, professionals and academics, other stakeholders and the affected communities including tenants and owners. The organizational structure of the Authority is shown in Fig. (1).

\section{Redevelopment}

Redevelopment usually targets old, dilapidated buildings with poor living conditions. These deteriorated sites are planned again and rebuilt to achieve environmental and social benefits such as open space and community facilities. In general practice, the Urban Renewal Authority assembles larger areas of land for comprehensive planning. This enables restructuring, for instance of the local transport network and open spaces, to better utilize land and to improve the district environment as a whole [27].

\section{Rehabilitation}

The URA works with property owners, the Government and other partners to prevent the decay of the built environment by promoting and facilitating the proper repair and maintenance of buildings. Rehabilitation helps extend the useful life of buildings and alleviates the urgency of redevelopment. To this end, a range of measures including advisory, incentive loans, grants, and insurance schemes 


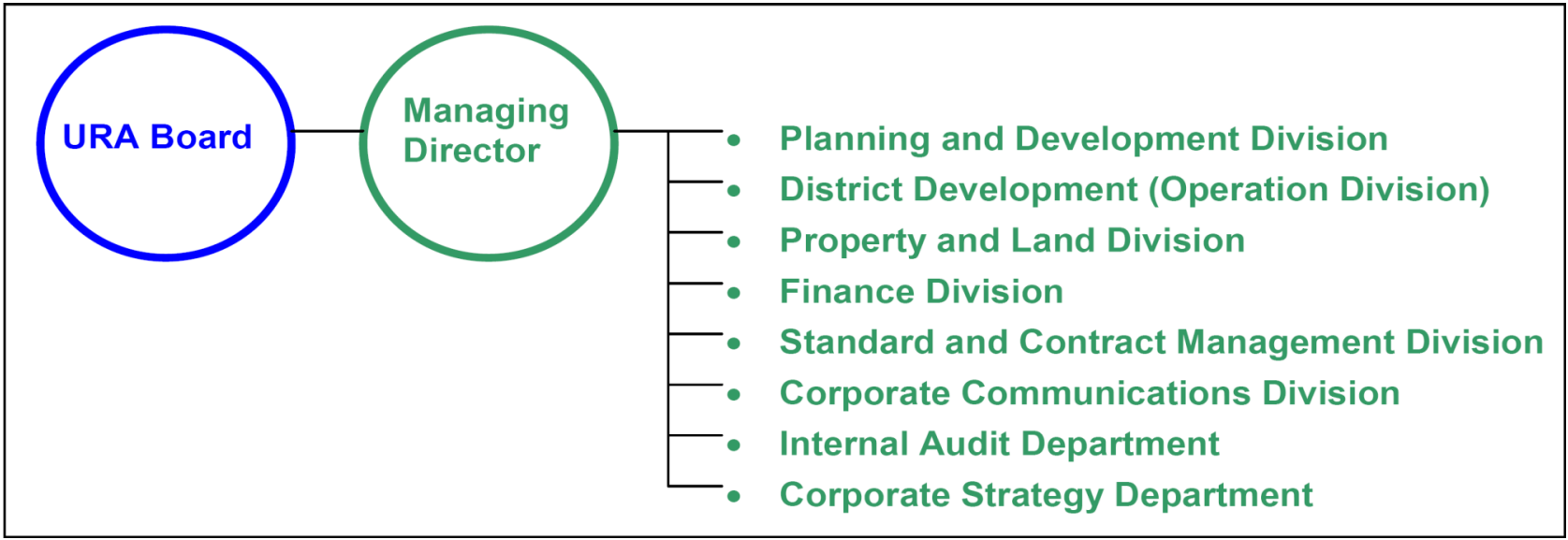

Source: [27], redrawn by author.

Fig. (1). Organization structure of Urban Renewal Authority.

have been introduced by the URA in order to encourage owners to rehabilitate their buildings [28].

\section{Revitalisation}

'Revitalisation is the deployment of appropriate means of renewal to revive and strengthen the economic and environmental fabric of different districts' [29]. The URA's 'holistic' and coordinated approach involves its partners and different stakeholders to improve the quality of urban living through redevelopment, rehabilitation and preservation initiatives, combined to revitalize the old urban districts (Fig. 2).

\section{Preservation}

Heritage buildings and places of local interest are important assets of Hong Kong. Urban renewal could positively contribute to enhancing the uniqueness and local character of the city as an international metropolis by preserving buildings of heritage value and enhancing places that are of historical, cultural or architectural importance (Fig. 3). 'Under its mandate to preserve buildings, sites and structures of historical, cultural or architectural interest that forms part of its redevelopment projects, the URA is looking at the issue of conservation in a comprehensive, holistic and



Source: [26].

Fig. (2). Sheung Wan revitalisation project: Sheung Wan Fong. 
practical manner' [30]. The URA has been involved in the management, conservation and adaptive re-use of several projects including the Western Market, a Declared Monument in Central and Western District, as well as several pre-war shop houses at No.18 Ship Street, No.60-66 Johnston Road (Johnston Road redevelopment project) and No.186-190 Queen's Road East (Lee Tung Street / McGregor Street redevelopment project) respectively in Wanchai District.

The Urban Renewal Strategy suggests that the 'URA should consider setting up an advisory committee under its Board to advise on preservation work' [28] The responsibility for overseeing the preservation work rests with the URA's Planning, Development and Conservation Committee (PDCC), as one of its functions is 'to assess, review and recommend proposals for the conservation of buildings, sites and structures of historical, cultural or architectural interest' [30]. The PDCC set up a Conservation Advisory Panel, comprising four to six local and international advisers, to provide advice to the URA and the PDCC on proposals for heritage preservation as part of a wider revitalization of some districts, and more specifically, of the conservation and adaptive re-use of specific heritage buildings and features.

The Panel began meeting in Hong Kong in September 2002. Among its conclusions are that 'the URA should help educate the public and improve public awareness regarding conservation issues', 'forums with concerned government representatives should be held on a regular basis to exchange views and identify solutions to conserve issues in Hong Kong', and 'potential conservation features and buildings should be considered in a wider local context rather than on an individual basis' [30]. Due to these conclusions, a series of consultation forums were conducted in the planning process of Kai Tak, which led to public debates regarding controversial issues, including the focus of this paper - the conservation of the runway.

The preservation and improvement of heritage buildings are advocated in many urban renewal projects in Hong Kong, whereby the heritage buildings should be revitalized for more productive and beneficial uses. In many cases, the Lands Department in liaison with the Antiquities and Monuments Office (AMO) was requested to explore the feasibility of preserving the potential and after-uses of the buildings of heritage value sitting on Government land [31]. Imaginative design solutions are vital to preserve those heritage buildings and their adjoining areas as part of a comprehensive redevelopment scheme.

In this paper, the focus of interest - the runway - is not a 'building' but a 'feature' of local interest. It is historically linked to the site and is regarded as an important asset of the city by the majority of local citizens. Different views have been gathered regarding the future development of the runway. Some participants support its preservation. Others support a more adaptive and beneficial reuse of the runway, which would return the harbour to Hong Kong's citizens and leave the waterfront for public enjoyment. Others want to maximize the site's economic value by using it for commercial or high-rise residential buildings. So, the runway issues remain controversial in the redevelopment process of Kai Tak. In this paper we look at the different views expressed by the different stakeholders about the different uses the runway should be put to. We also hope to show that the approach used by URA to preserve the runway is different from that adopted for other projects. We will also discuss the proposals, motives, and agendas of the main participants, and how they promote their respective interests.

\section{THE KAI TAK AIRPORT}

Kai Tak is the name of a prime piece of reclaimed land that served as the old international airport of Hong Kong from 1925 until 1998. At the stroke of midnight, 5th July 1998 , this vibrant and famous airport that once served as an important commercial and cultural gateway to Hong Kong and mainland China was replaced by the new Hong Kong International Airport at Chek Lap Kok, off Lantau Island. Hemmed to the north by high-rise housing estates and the mountains that separate Kowloon from the New Territories, and with its single runway jutting out into Victoria Harbour, the airport was known by visitors for its spectacular, lowaltitude landings [32]. There was only one runway at Kai Tak, oriented at 136.1 degrees and 316.1 degrees, hence its name is $13 / 31$. The runway was built by reclaiming land from the harbour and was extended several times since its initial construction. The final length of the runway was $3390 \mathrm{~m}$. At the northern end of the runway, buildings up to six storey rose just across the road. The other three sides of the runway were surrounded by Victoria Harbour (see Figs. 4-8), making this piece of land particularly valuable. The government wants to make use of this unique harbour-front site to create a new image for Hong Kong and enhance the quality of living in Hong Kong [33]. A vibrant and elegant urban living experience, as well as an environmentally attractive and sustainable development, are anticipated in this piece of valuable asset [33].

Kai Tak was never an ideal site for an airport. Although there were no serious accidents at the airport during its long life, the potential loss of life from an aircraft crash grew alarmingly during the $1970 \mathrm{~s}$, as high-rise residential developments sprung up all around the airport. During the 1980 s, as Kai Tak airport approached its capacity limit, the Hong Kong Government began searching for a site for a replacement airport. Eventually, the government settled on the remote island of Chek Lap Kok off Lantau Island and Kai Tak was subsequently retired. The new airport is located well away from Hong Kong's main residential developments, minimising the dangers of a major crash and also minimising the nuisance of noise pollution.

The former site of the airport has remained vacant since 1998. Considering its 'sky high price' and its favourable location by the harbour, this is a regrettable waste of valuable land. Planning for the redevelopment of the site began in the early 1990s, and continues to this day. The Kai Tak Planning Review, which began in July 2004, was followed by a series of organized public forums and meetings. Consolidated public views, including development themes have been gathered and Outline Zoning Plans have been published. Apparently the ultimate vision is to achieve 'A Distinguished, Vibrant, Attractive and People-oriented Kai Tak by Victoria Harbour' [36]. However, many issues regarding the redevelopment of the area have been very controversial, with different stakeholders expressing conflicting, irreconcilable opinions. 




The house (18, Ship Street) was built by the owner's grandfather in late1930s. It was originally made of timber, but during World War II, the house fell into disrepair. The family rebuilt the whole property after the war.
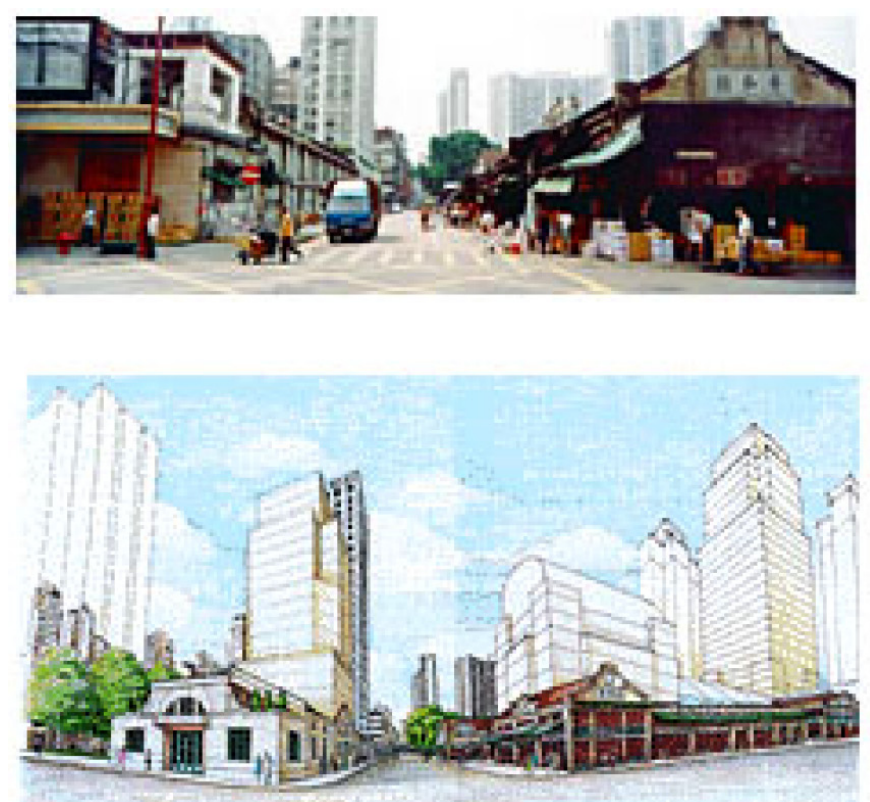

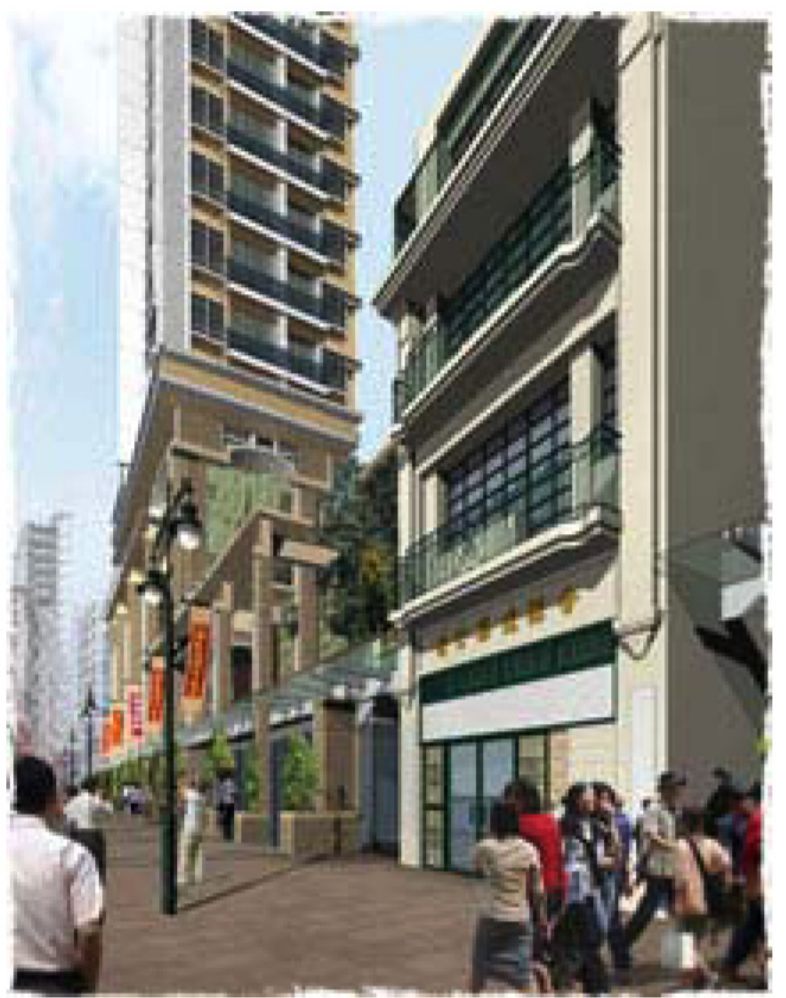

Artist's impression of the restored building.
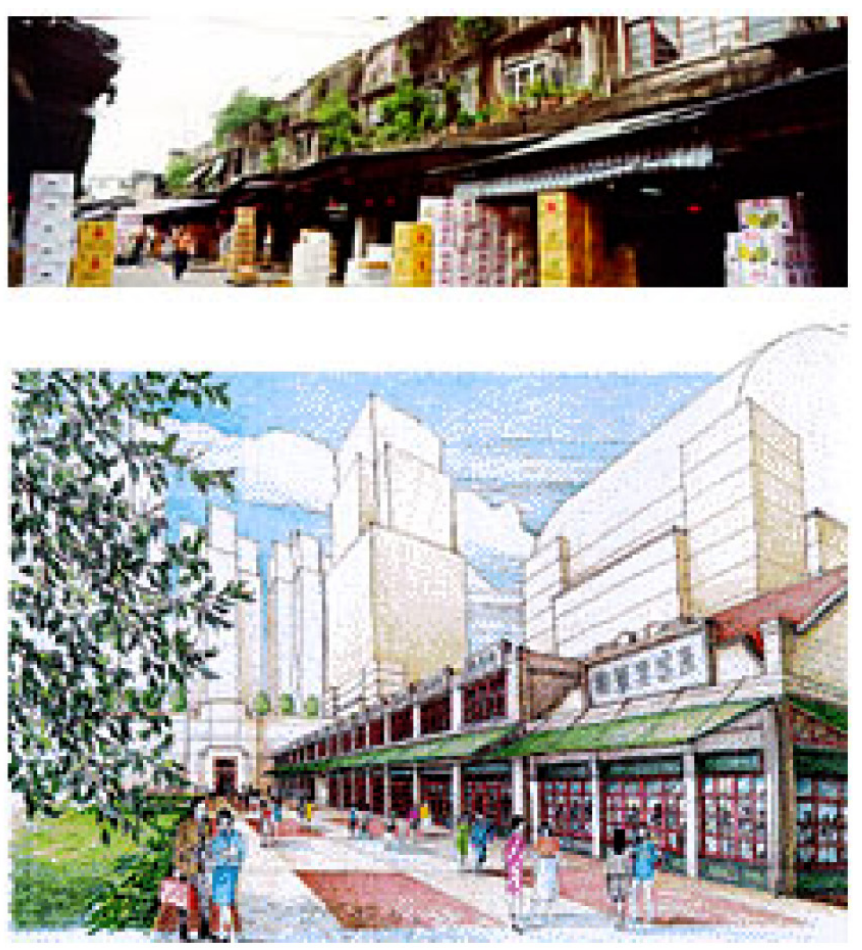

Yau Ma Tei Cinema and Wholesale Fruit Market Preservation Scheme

Source: [26].

Fig. (3). Examples of preserved buildings. 


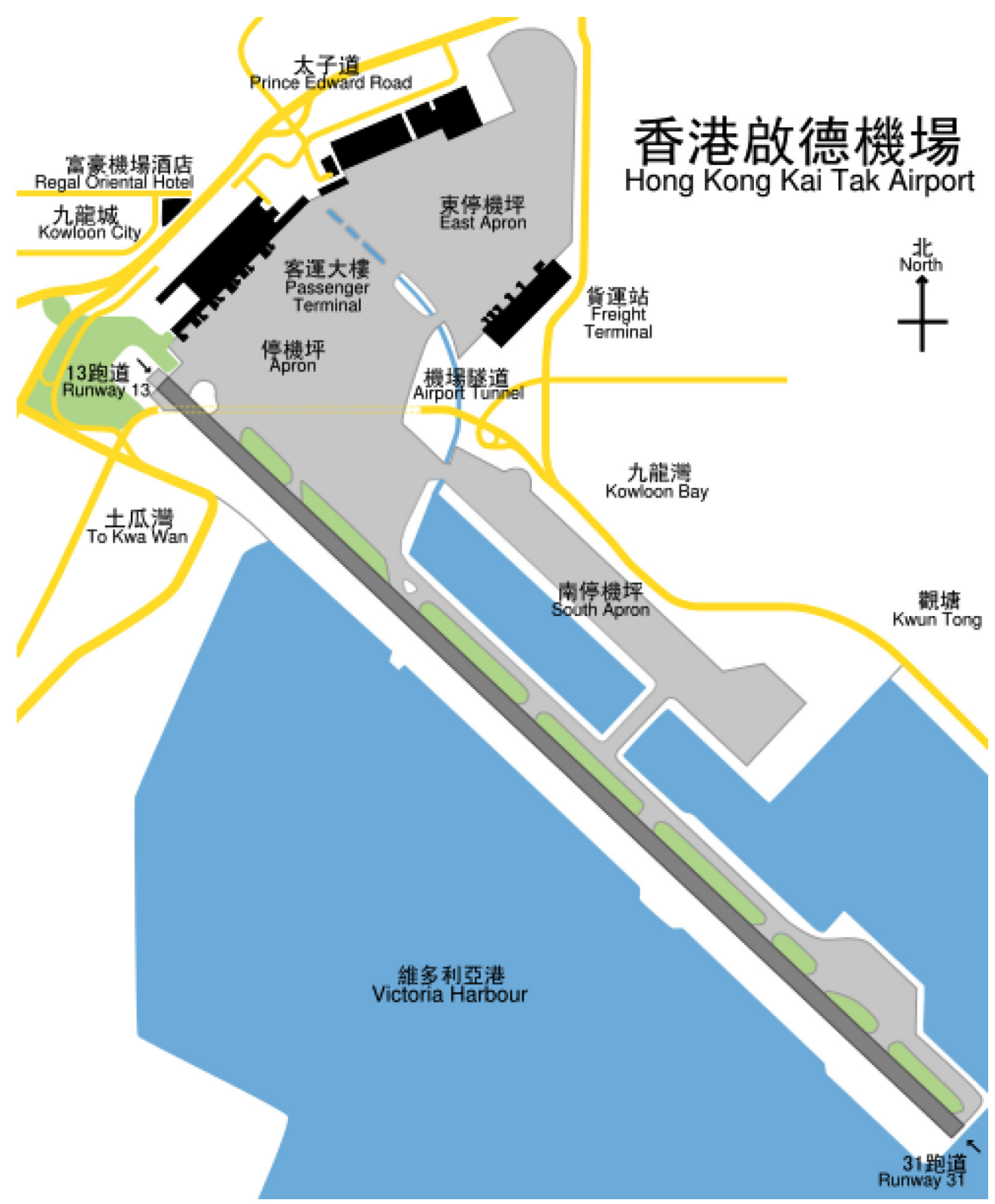

Source: [34].

Fig. (4). Map showing the Kai Tak site.

While the government might genuinely attempt to strike a balance between the conflicting ideas, it is obviously not possible to please all stakeholders.

Since the regeneration project is 'people oriented', the government recognizes the importance of public participation in the planning process. Public involvement/ participation and social impact assessment (hereafter referred to as SIA) should contribute to the process of redevelopment. The public involvement process is a means of collecting valuable data on specific SIA variables. Interviews, workshops, public meetings, surveys etc., are all means to encourage public participation and the possible effects on the local social structures can be easily understood by looking at the information collected. The issue about community participation raises many questions concerning the extent and validity of the knowledge and opinions of local communities, and the right of them to determine their own destinies independent of outside interference [37, 38]. SIA is most successful when fully integrated into planning at the appropriate level of jurisdiction [37]. With this integration accomplished, both social and environmental factors become the central considerations for decision making, rather than 


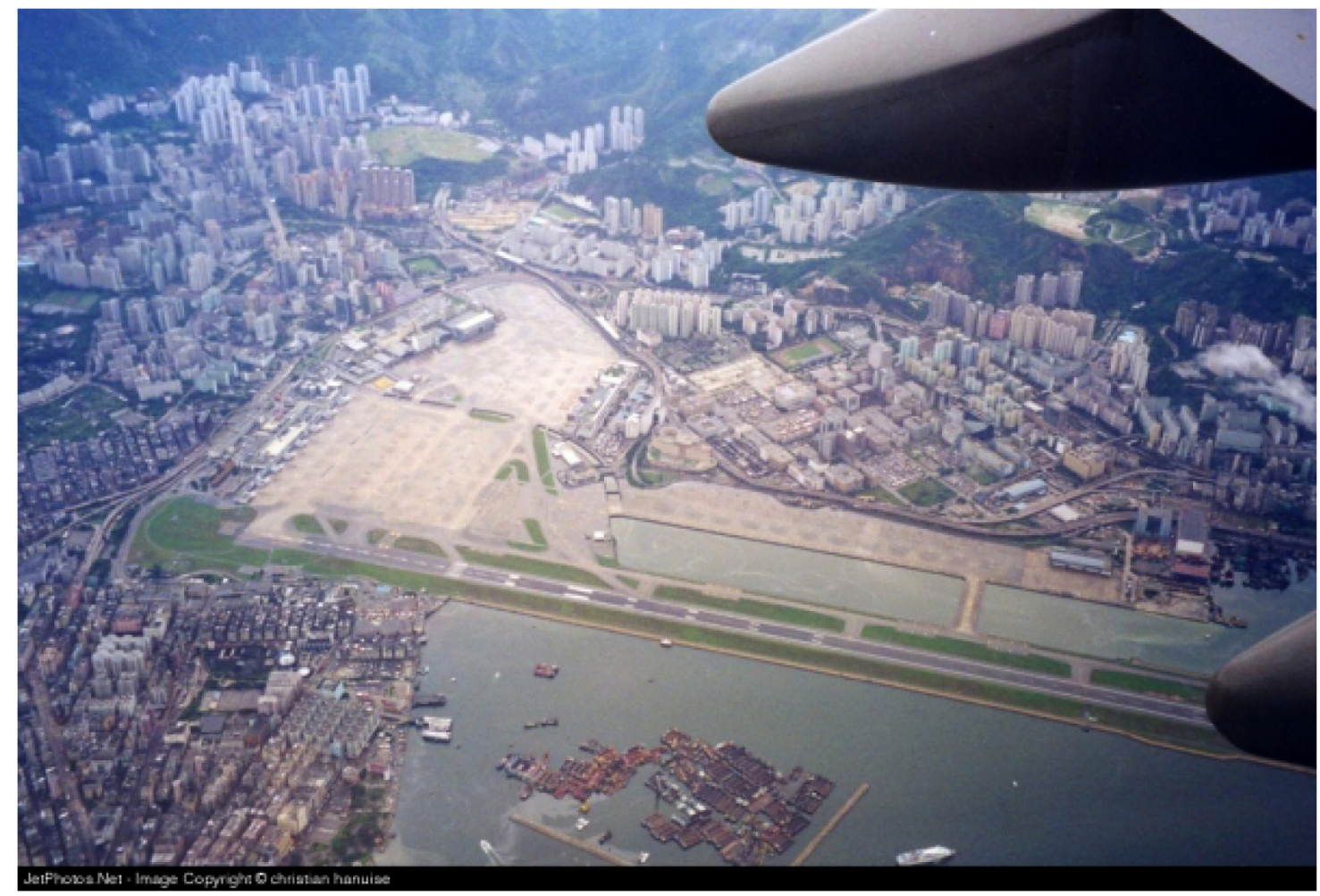

Source: Christian Hanuise [35].

Fig. (5). Overfly of Kai Tak Airport the first day after closure (6th July 1998).

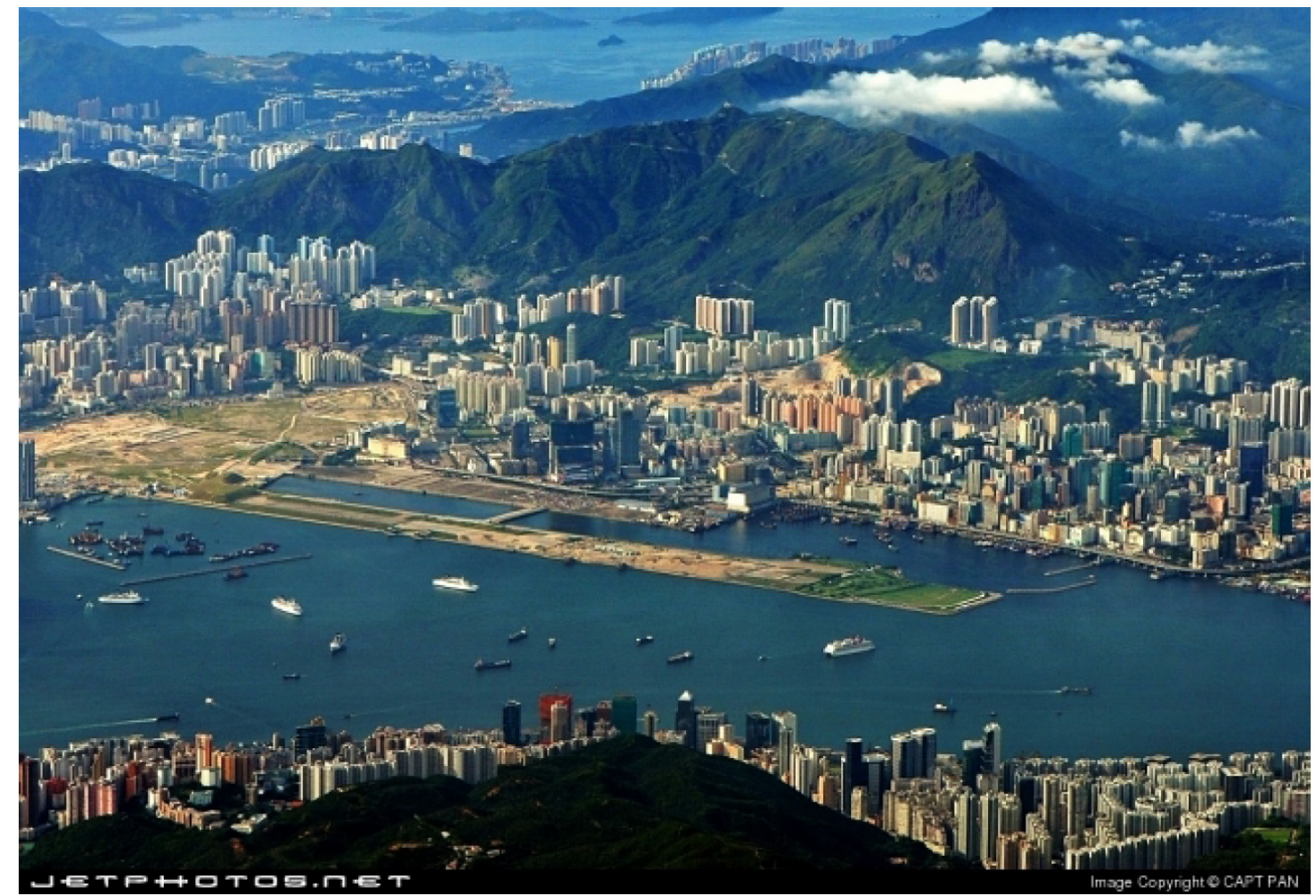

Source: Capt. Pan [35].

Fig. (6). Kai Tak, 4 August 2006.

being treated as external or peripheral to the planning process.
The Kai Tak Redevelopment Project is 'people-oriented' in the sense that the government launched a series of public consultations in order to give the local citizen an opportunity 


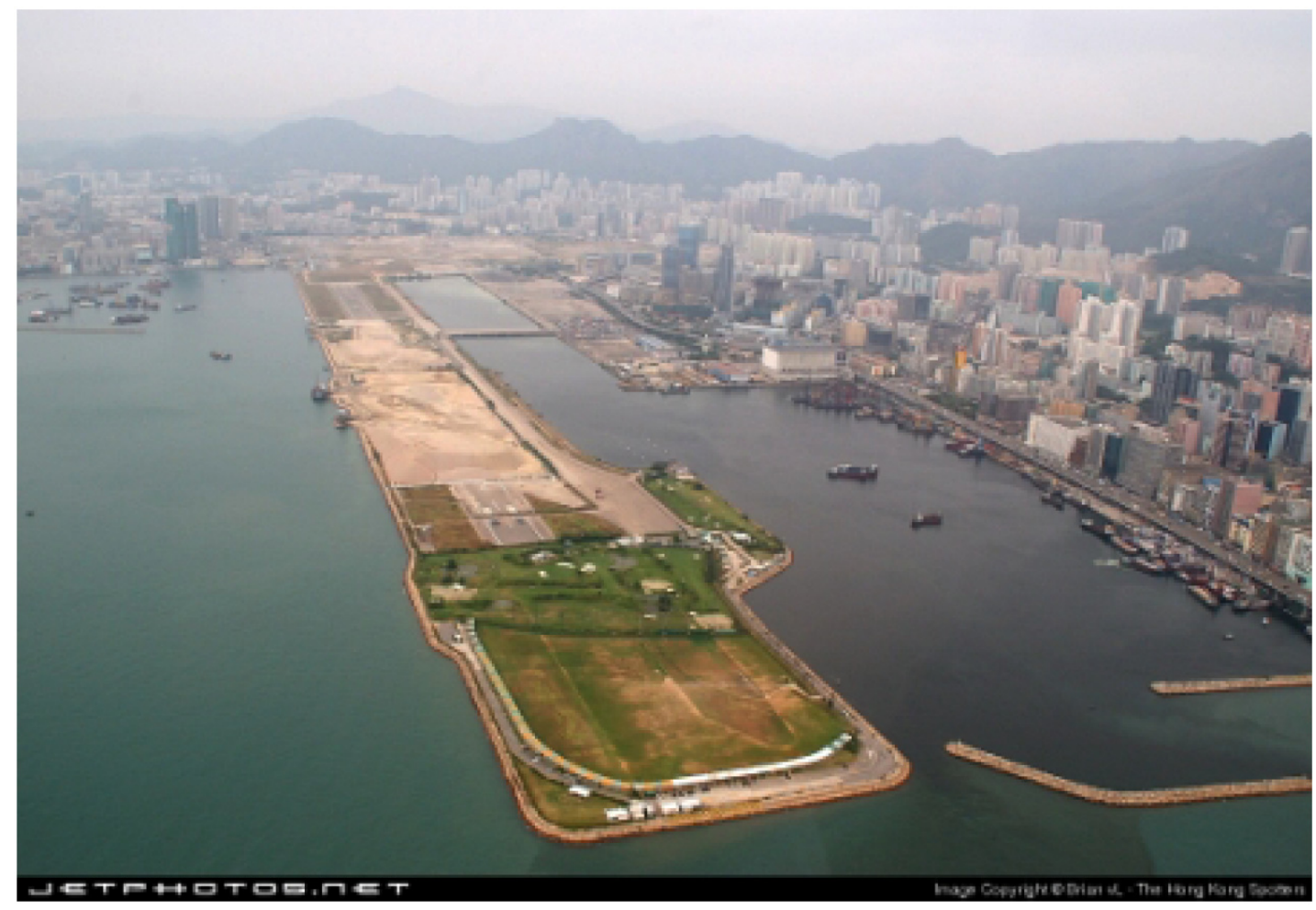

Source: Brian vL [35].

Fig. (7). The Runway on 31 October 2005: the land is vacant at the moment.

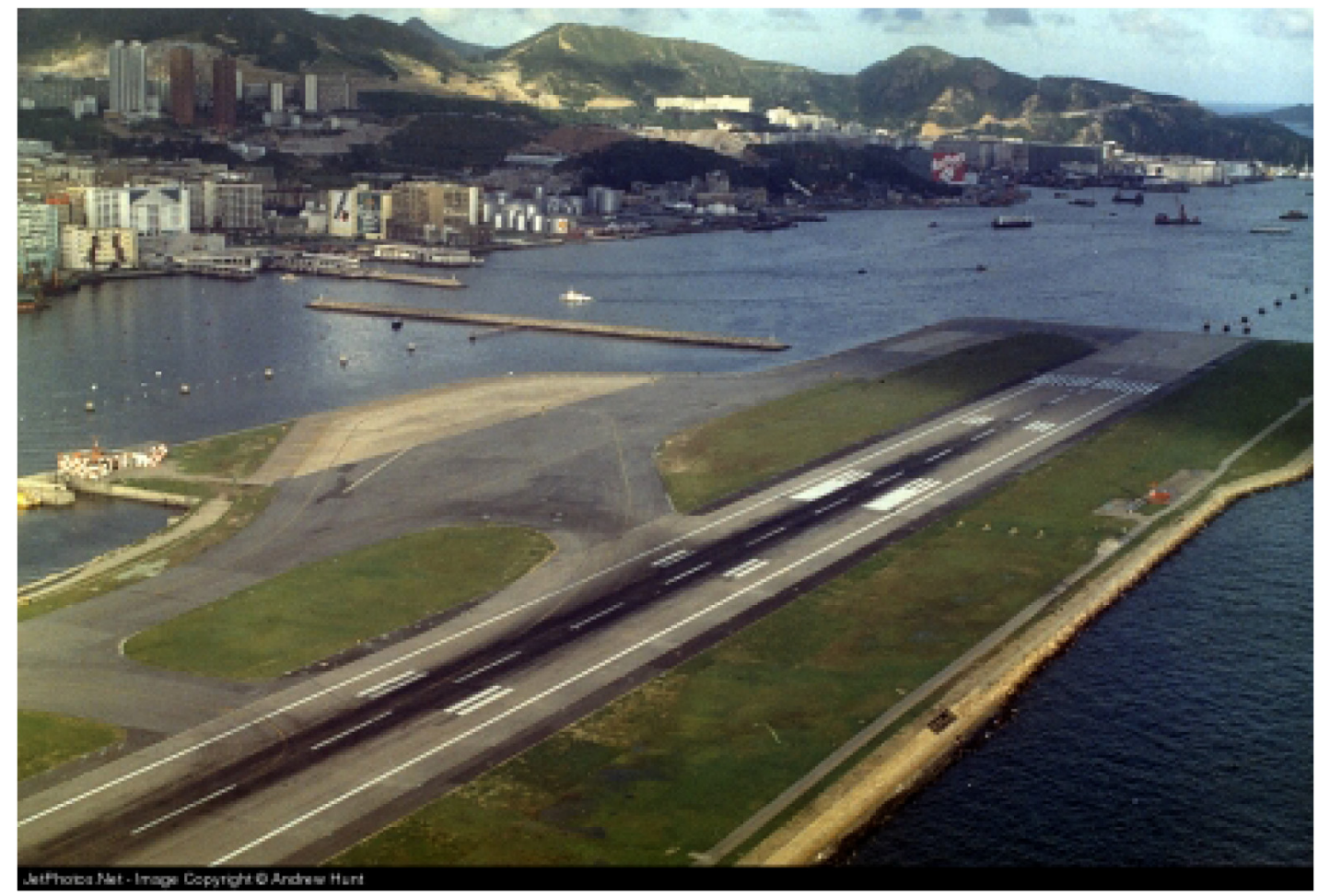

Source: Andrew Hunt [35].

Fig. (8). Runway 31.

to express their points of view. However, conflicts arose during - and because of - these meetings and forums. By consulting the published digests and planning reviews we can identify the stakeholders involved and their standpoints.
However, before moving onward to look at the arguments expressed about the Kai Tak Runway, let us first briefly review the planning history of Kai Tak. 


\section{Planning History of Kai Tak}

In October 1998, a draft new plan for the old Kai Tak Airport site was proposed by the government, involving the reclamation of 219 hectares. Since the draft involved largescale reclamation, a large number of objections were received and therefore the government scaled it down to 166 hectares in June 1999. The Territorial Development Department conducted a new study on the future development of the site, entitled 'Feasibility Studies on the Revised Southeast Kowloon Development Plan' which commenced in November 1999, and a public consultation was conducted in May 2000, when land reclamation was further scaled down to 133 hectares. These new plans, based on the feasibility studies, were approved by the Chief Executive in July 2002. The approved plans included housing development in Kai Tak, aiming to house around $240,000-340,000$ residents. However, due to calls from the public to protect the harbor and participate more deeply in future town planning, the plans were put on hold. The scale and plans of the project are yet to be settled upon [36].

A number of proposals regarding the runway were also made, not all of which envisaged its preservation. There were proposals to dredge the runway to form several islands for housing, to build a terminal capable of accommodating cruise ships the size of the Queen Mary 2, and latterly, to house the Hong Kong Sports Institute [36]. On January 9, 2004 the Court of Final Appeal in Hong Kong ruled that no reclamation plan for Victoria Harbour could be carried out unless it passed an 'overriding public interest' test [39]. Subsequently, the plans proposed in July 2002 were abandoned. In July 2004, the government set up a 'Kai Tak Planning Review' for further public consultation. A number of blueprints were then generated. Figs. (9-11) show how the Review works and how consultation meetings and forums were organized.

In Stage 2 Public Participation (Nov 2005 - Jan 2006, Fig. 11), 7 public forums were organized, 20 briefing sessions were arranged to major statutory/ advisory bodies and stakeholder groups, with over 500 participants taking part, and over 150 written submissions received [41]. The next section will analyse the concerns raised and the opinions expressed by stakeholders and the general public during these forums and briefing sessions.

Two major plans were published in 2006 at the end of the Planning Review (Fig. 11). First, a blueprint published in June 2006 proposed that hotels would be scattered throughout the 328-hectare site, and there would be flats aimed at housing 86,000 new residents. Other 48 features of the plan included two planned cruise terminals and a giant stadium. Second, on October 17, 2006, the Planning Department unveiled a major reworking of its plans for the old Kai Tak airport site, containing 'a basket of small measures designed to answer a bevy of concerns raised by the public' [42]. The revised blueprint suggested the extension of several 'green corridors' from the main central park into the surrounding neighbourhoods of Kowloon City, Kowloon Bay and Ma Tau Kok. Proposed features included a 200-metre high public 'viewing tower' near the tip of the runway, with hotel spaces to be centralized near the end of the runway, to face out into the harbour towards Central, while a second row of luxury residential spaces would face Kwun Tong and be placed on an elevated terrace or platform to preserve the view of the harbour. A new bridge at the end of the runway would have joined the hotel district with

\section{Kai Tak Planning Review}



Source: [40].

Fig. (9). Kai Tak Planning Review. 


\section{Kai Tak Planning Review : Stage 1 to Stage 2}

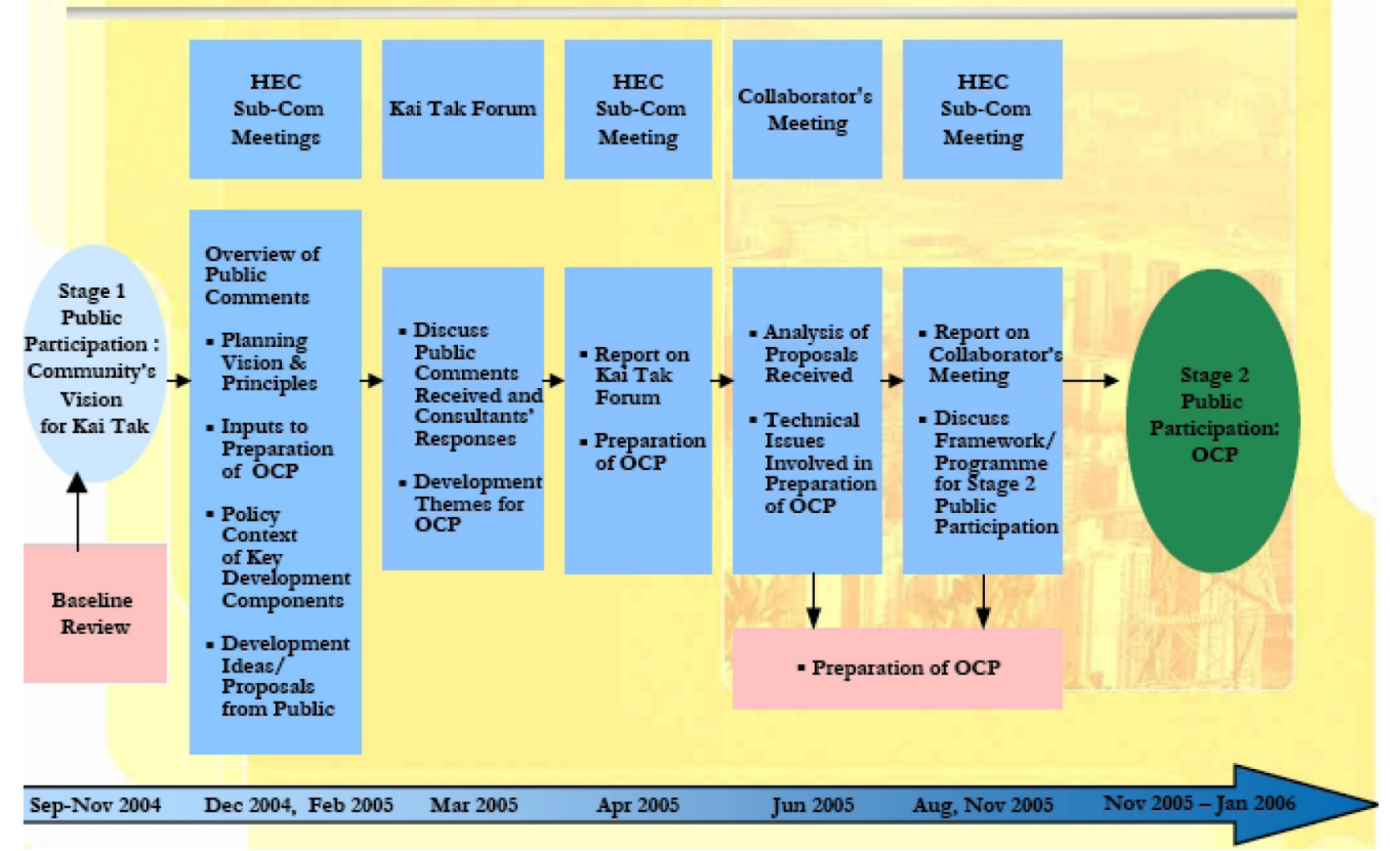

Source: [40].

Fig. (10). Kai Tak planning review.

\section{Kai Tak Planning Review: Stage 2 to Stage 3}

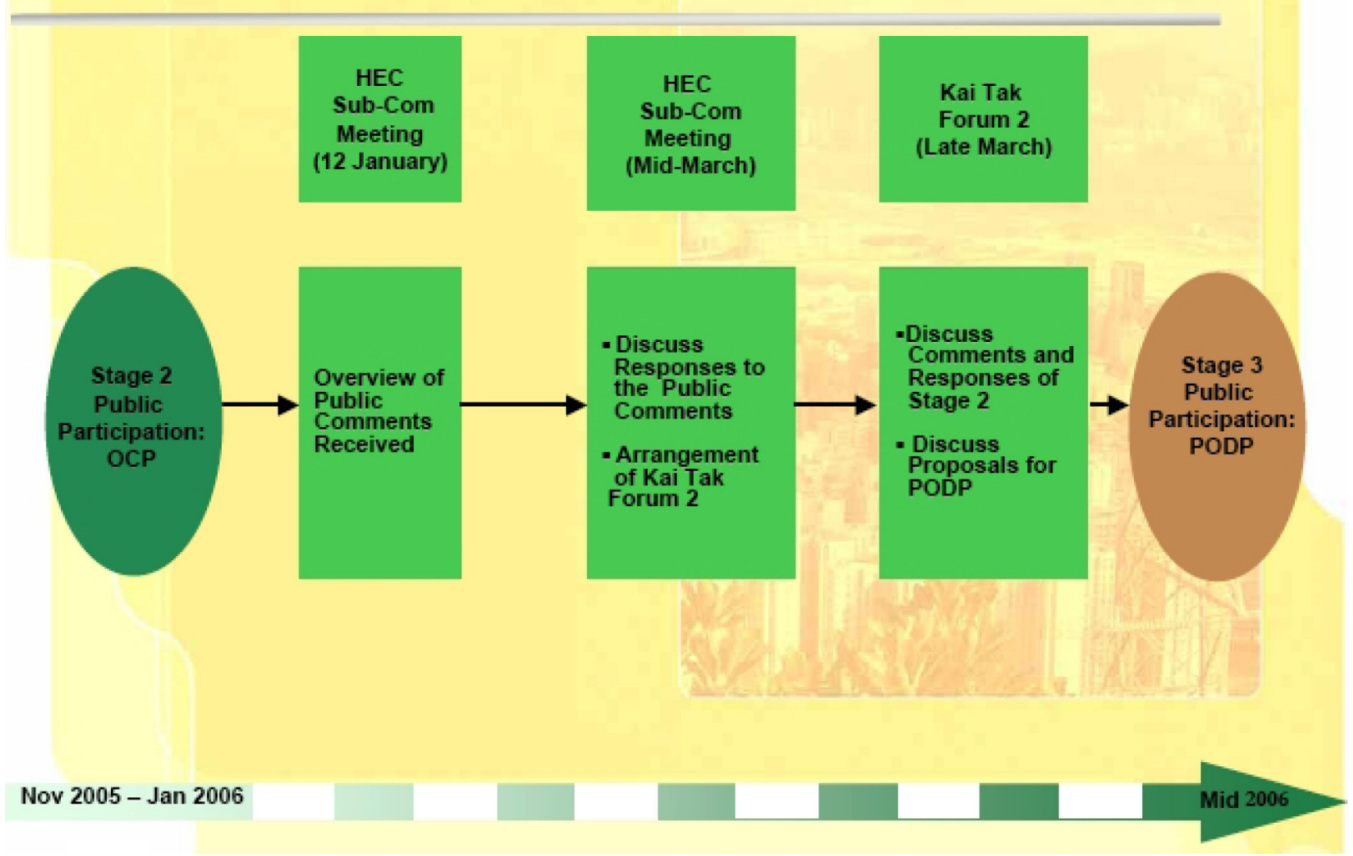

Source: [40].

Fig. (11). Kai Tak planning review.

Kwun Tong [42]. These plans were criticized by different stakeholders, as we will see in the following pages.

\section{ANALYSIS OF THE PLANNING PROCESS}

Based on the papers, consultation digests published by the planning department, presentations of various organizations and newspaper articles, we will identify the participants involved in the planning of Kai Tak, as well as their views expressed about the preservation and use of the runway. This will allow us to delve on their respective motives and the agendas behind their proposals, and on the ways in which they promote their interests. Before moving 
Table 1. Proposals and Stakeholders

\section{Preservation of the Runway}

\begin{tabular}{|l|l|}
\hline \hline \multirow{5}{*}{ Pro - reclamation } & HKAC (Hong Kong Aviation Club) - \\
& KTPDCG (Kai Tak Planning and Development Concern group ) - \\
& BPFHK (The Business and Professionals Federation of Hong Kong) - \\
& HKHS (Hong Kong Housing Society) - \\
& HKKCICA (Hong Kong Kowloon City Industry and Commerce Association) - \\
& HKPRI (Hong Kong Policy Research Institute) - \\
& KCDC (Kowloon City District Council) - \\
& KTCBA (Kwun Tong Community Builder Alliance) - \\
& SWIRE (Swire Properties Ltd.) - \\
& Property Owners of Yau Tong Bay - C.Y. Jim - H.H. Li - J.Gao - L.Huang \\
\hline \multirow{5}{*}{ No reclamation } & HKIP (Hong Kong Institute of Planners ) - \\
& HKKMBTBAL (Hong Kong \& Kowloon Motor Boats \& Tug Boats Association Ltd.) - \\
& HKPRI (Hong Kong Policy Research Institute) - \\
& RLC (Recreation of Local Culture) \\
\hline \multirow{5}{*}{ Preservation of history } & HKFTU (Hong Kong Federation of Trade Unions) - HKIVE (Hong Kong Institute of Vocational Education)- \\
& KTCBA (Kwun Tong Community Builder Alliance) - \\
& RLC (Recreation of Local Culture) - \\
& BPFHK (Business and Professional Federation of Hong Kong) - \\
& Kwun Tong RA (Kwun Tong Resident Association)- \\
& Community Workshop \\
\hline \multirow{3}{*}{ Braking of the runway } & SWIRE (Swire Properties Ltd.) - \\
& Community Workshop - \\
& REDA (The Real Estate Developers Association of Hong Kong) - \\
& Planning Department \\
\hline
\end{tabular}

Use of the Runway

\begin{tabular}{|c|c|}
\hline Quality residential housing & $\begin{array}{l}\text { HKIP (Hong Kong Institute of Planners) - } \\
\text { HKHS (Hong Kong Housing Society) - } \\
\text { KCDC (Kowloon City District Council) - } \\
\text { SWIRE (Swire Properties Ltd.) - } \\
\text { REDA (The Real Estate Developers Association of Hong Kong) - } \\
\text { HKGCC (Hong Kong General Chamber of Commerce) - } \\
\text { Planning Department }\end{array}$ \\
\hline $\begin{array}{l}\text { Against residential } \\
\text { development }\end{array}$ & $\begin{array}{l}\text { HKIS (Hong Kong Institute of Surveyors )- } \\
\text { HKPRI (Hong Kong Policy Research Institute Limited) - } \\
\text { SKTC (Save Kai Tak Campaign) - } \\
\text { Citizen A. Chan }\end{array}$ \\
\hline Cruise terminal & $\begin{array}{l}\text { BDFHK (The Business and Professionals Federation of Hong Kong) - } \\
\text { HKIS (Hong Kong Institute of Surveyors )- } \\
\text { HKPRI (Hong Kong Policy Research Institute Limited) - } \\
\text { KCDC (Kowloon City District Council) - } \\
\text { KTCBA (Kwun Tong Community Builder Alliance) - KTPDCG (Kai Tak Planning and Development Concerned } \\
\text { Group) - } \\
\text { Hong Kong Tourism Board }\end{array}$ \\
\hline $\begin{array}{l}\text { Against the construction of cruise } \\
\text { terminal }\end{array}$ & $\begin{array}{l}\text { HKDC (Hong Kong Delivery Company)-- } \\
\text { REDA (Real Estate Developers Association) - } \\
\text { SKTC (Save Kai Tak Campaign) - } \\
\text { NTCTA (New Territories Cargo Transport Association) }\end{array}$ \\
\hline Aviation-related facilities & $\begin{array}{l}\text { HKIS (Hong Kong Institute of Surveyors )- } \\
\text { SKTC1 (Save Kai Tak Campaign 1)- } \\
\text { HKPA (Hong Kong Parachute Assocation)- } \\
\text { HKAC (Hong Kong Aviation Club)- } \\
\text { HKPRI (Hong Kong Policy Research Institute Limited) - } \\
\text { SKTC2 (Save Kai Tak Campaign 2) - } \\
\text { HKIP (Hong Kong Institute of Planners) - } \\
\text { HKFTU (Hong Kong Federation of Trade Unions)- } \\
\text { SWIRE (Swire Properties Ltd.) - } \\
\text { HKIVE (Hong Kong Institute of Vocational Education) - } \\
\text { Greenwatch - } \\
\text { HKACC (Hong Kong Air Cadet Corps) - } \\
\text { Community Workshop }\end{array}$ \\
\hline Against aviation-related facilities & $\begin{array}{l}\text { Civil Aviation Department - } \\
\text { Planning Department }\end{array}$ \\
\hline
\end{tabular}

into the analysis, Table 1 summarises the broad proposals of the different stakeholders. However, we will not describe all proposals. In what concerns the preservation of the runway we will only focus on two options: that of preserving the unique shape and history of the runway, and that of intersecting the runway so as to create artificial islands. On the other hand, in what concerns the use of the runway we will only focus on the conflicts between the groups suggesting residential development and those suggesting the development of aviation facilities.

\section{PRESERVATION ISSUES}

In June 2002, the Outline Zoning Plans were approved by the Chief Executive in Council, and in July 2002 they were gazetted for public inspection. In the Outline Zoning Plans, three concept plans (Figs. 12-14) were proposed by the 




Source: [36].

Fig. (12). Concept Plan 1.

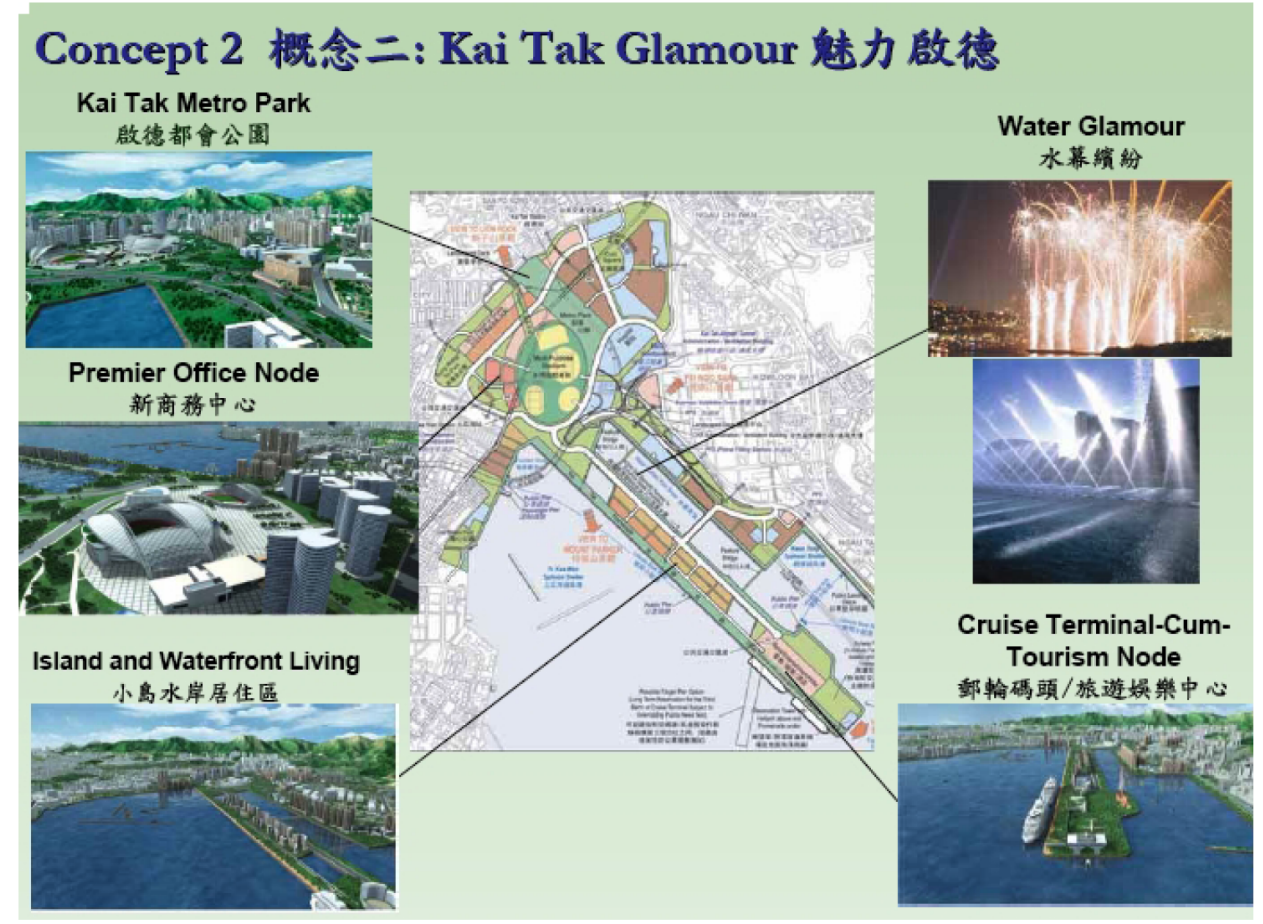

Source: [36].

Fig. (13). Concept Plan 2.

Planning Department. They are City in the Park, Kai Tak Glamour and Sports by the Harbour, respectively [36]. These concept plans were subsequently the subject of public consultation.
In both the concept plans of City in the Park (Fig. 12) and Kai Tak Glamour (Fig. 13), the components 'island and water front living' are included. This component involved cutting the runway and create a series of islands so as to maximize the waterfront for development, and to relieve the environmental problems of the Kai Tak Approach Channel 




Source: [36].

Fig. (14). Concept Plan 3.

(KTAC). We first look briefly at some background information about the reclamation and the KTAC issues, in order to understand the whole concept of cutting the runway into islands, hence alleviating the environmental problems.

\section{ISSUES ON RECLAMATION}

The earliest studies of Kai Tak Development focused on the optimisation of the development potential of the old airport site with reclamation of the adjacent water bodies [33]. Due to the Judgment of the Court of Final Appeal on the draft Wan Chai North Outline Zoning Plan handed down in January 2004, all development proposals that involve harbour reclamation are required to fulfil the 'overriding public need' test [33]. In accordance with the principle of presumption against reclamation enshrined in the Protection of Harbor Ordinance, the Kai Tak Study had adopted a "no reclamation' development scenario as a starting point [33]. The general population, the environmental groups and some stakeholders such as HKIP, Hong Kong and Kowloon Motor Boats \& Tug Boats Association Ltd (HKKMBTBAL), HKPRI, Recreation of Local Culture (RLC) etc., support this approach. Yet, there are also groups that think there is a need for reclamation. Some citizens think that the reclaimed land in Kai Tak could provide space to meet the requirements of the interface areas. Societies like Hong Kong Aviation Club (HKAC) and Kai Tak Planning and Development Concern group (KTPDCG) considered a little reclamation acceptable for the purpose of enlivening the existing waterfront and to provide essential facilities. The 'smelly water' of the KTAC and 'unsightly structures' had been referred to by The
Business and Professionals Federation of Hong Kong (BPFHK) as a vital concern. It was argued that the principle of bringing the harbour to people and vice versa won't be fulfilled because people can hardly reach the waterfront with these problems. Moreover, strict adherence to the Protection of the Harbour Ordinance would make it difficult to resolve the odor problem so as to develop Hong Kong into an aesthetic waterfront city [36]. Actually, the reclamation issue depends mostly on the situation of the KTAC, where toxic mud is accumulated and where odour comes from. There are options to eliminate these problems and they will be discussed in the next paragraph. The 'no reclamation' scenario is likely to be put into action since there is no proved 'overriding public need' for reclamation.

\section{THE ENVIRONMENTAL PROBLEMS THREATENING THE KAI TAK APPROACH CHANNEL}

The reclamation of Kai Tak Approach Channel has been a controversial issue. Accumulation of contaminated sediments and odours resulting from anaerobic decomposition of the organic substances that exist in the surrounding waters are the major environmental problems threatening the development along the channel [43]. The majority favours the preservation of the runway and recognized the need to tackle the incumbent environmental problems. It is hoped that with proper treatment of contaminated mud, the Channel could be retained and upgraded for other uses, such as water sports like dragon boat-racing and skiing, waterfront restaurants/ marina etc. [36]. On the other hand, some stakeholders like HKHS, 
HKKCICA, HKPRI claimed that reclamation is the only permanent and possibly cost-effective solution to the existing problems [36]. In the EIA reports on KTAC, three reclamation options were proposed, with different implications for treatment of approximately $860,000 \mathrm{~m}^{3}$ of contaminated sediments [43]:

- no dredged reclamation, with in-situ treatment

- fully dredged reclamation, with ex-situ treatment

- $\quad$ minimum dredged reclamation, with either in-situ or ex-situ treatment

It is argued that if the odours are caused by the presence of toxic mud, and reclamation will not solve the problem permanently as well because the contaminated mud will still be underneath the reclaimed land. Various ways were proposed to try to address these environmental problems. The most commonly recommended way is to break through the runway to enhance water circulation hence to improve the water quality [36]. At present it is thought that the best way to resolve these problems will be decided upon further technical assessments.

\section{PRO-RECLAMATION}

The reclamation of the runway means that the shape of the runway will not be retained. There are departments and organizations which are in favour of reclaiming Kai Tak. They include HKHS, HKKCICA, HKPRI, KCDC, KTCBA, KTDCG, property owners of Yau Tong Bay and Swire, which all support reclaiming KTAC to solve its environmental problems [44]. KTDGC supports reclamation since there will be more land for residential redevelopment. Swire stresses that reclamation is a permanent and costeffective way to solve the odour problem [45]. Groups that are eager to preserve the unique shape of the runway, particularly the Save Kai Tak Campaign, of course, oppose the reclamation plan.

\section{AN ALTERNATIVE - BREAKING THE RUNWAY}

Because of the existing odour problem and the "no reclamation scenario' adopted by the Planning Department, it is understandable that plans involving cutting the runway were suggested in the Outline Concept Plans (refer to Figs. 12, 13) in stage 2 of the Planning Review. As mentioned, some organizations such as HKHS, HKKCICA, HKPRI, KCDC and KTCBA think that reclamation is the best solution to solve the odour problems. Citizens like C.Y. Jim, H.H. Li, J. Gao and L. Huang claimed in the public consultation that the reclamation option is worth exploring since there would be more land for development and it would provide flexibility in setting out the layout for Kai Tak [36]. So, if there will not be reclamation, cutting the runway to allow better water flow would be an alternative option to relieve the pollution problem of the KTAC. Therefore, different interests groups with various motives came up with the 'islands' plan with various arguments. Stated in the Outline Concept Plans published by the Planning Department, removing sections of the runway will help enhance tidal flush, thus alleviating the problem [36]. Swire came up with the archipelago design, claiming that having canals intersecting the runway would maximize waterfront space and that a spectacular series of islands extending into the harbour could improve viewing areas and create island neighbourhoods [45]. The Community Workshop also supports breaking the runway, saying it allows better water circulation at KTAC, which would facilitate water park/ sports [36].

\section{First Option: Support for the Preservation of the Runway}

Most of those who are eager to preserve the runway and local history do not support breaking the old airport runway. They emphasize the significance of local aviation history and wish for the preservation of the whole runway as an intact one. For this group of people, in retaining the local culture and the historical past of Kai Tak as an airport, the Kai Tak runway, with its unique shape, should be retained as a historical landmark of Hong Kong. As mentioned above, local heritage 'stands to reason that the best of our achievements should be preserved and cherished, as lasting contributions to the record of who we are and what we have accomplished' [1].

Kai Tak International Airport had been operated for almost 74 years, it was like a friend of Hong Kong people, experiencing ups and downs, wars, revolutions, and economic bloom in its period of operation. It is a legendary airport and it is worth retaining since it witnessed the past development and success of the city. It is not surprising that there is a considerable number of people attempting to retain the Runway 13. The retention of it could allow Hong Kong people to trace their own roots through their history and memories. As the world's most dangerous runway, possessing its own historical and architectural values, its retention would allow Hong Kong to retain unique local characteristics. According to BPFHK for example, the shape of the Kai Tak runway and the extensive water bodies at the Approach Channel serve as unique design features, and therefore should be retained [46]. Those involved in supporting the retention of the Kai Tak Runway include the HKFTU, HKIVE, KTCBA, Kwun Tong RA, RLC, BPFHK, SKTC, Community Workshop.

Among the advocators of the preservation of the runway, the Save Kai Tak Campaign is probably the largest and most influential. It has a wide network of supporters and has done a lot throughout the years to advocate the retention of the aviation culture remnant in Kai Tak. One of the slogans of this Campaign is 'Let's Save Kai Tak for GA (General Aviation)!! Support Save Kai Tak Campaign' [47]. Supporters of this group recognize the historical value of the old airport and the runway, they treat the ex-airport as a 'friend' and they regard it as former starting point to explore the outside world. Representatives from the Campaign said that local urban planning is in lack of flexibility, and it fails to fulfil the needs of the growing society. They stated that over-planning will just result in land uses that might not meet society's actual needs, and that rigid land use restriction is a drawback of Hong Kong land use development [47]. They also stressed that if we retain the old airport today, at least we would have the opportunity to change its land use in the future. However, if we give it up today, it will be gone forever and we wouldn't be able to go back [47]. The Save Kai Tak Campaign is probably the loudest and most influential group fighting to save the Kai 
Tak Airport and Runway 13. Its aim is not just to preserve the runway itself but also to promote General Aviation in Hong Kong. Its motives and rationale for promoting such plans will be discussed in the section regarding the use of the runway.

\section{REGARDING THE FUTURE USE OF THE KAI TAK RUNWAY}

The public has expressed various ideas on how the runway should be used in the future. The major conflicts lie between groups who favour the cruise terminal, those who go for General Aviation Facilities and those who are in favour of quality residential housing redevelopment. Referring to the Outline Concept Plans, Concept 1 is basically a residential development plan where components like 'high density residential development' and 'island and waterfront living' are included. The theme of this concept plan is 'to develop a quality living district in a park-like environment' [36]. According to the plan, the area consists of two distinct areas of pleasant living High density and high-rise residential / stadium district at the heart of the North apron area, and a distinctive runway island with medium-rise, medium-density housing redevelopments (Figs. 15-17).

Stakeholders such as Swire Properties Ltd. (Swire) and The Real Estate Developers Association of Hong Kong (REDA) are clearly in favour of the intense residential developments in the Kai Tak area, especially the runway (for island and waterfront living).

\section{Second Option: Housing Development}

According to Louis Loong [48], secretary general to REDA, the development theme of Kai Tak 'should be a



Source: [36].

Fig. (15). City in the park. 


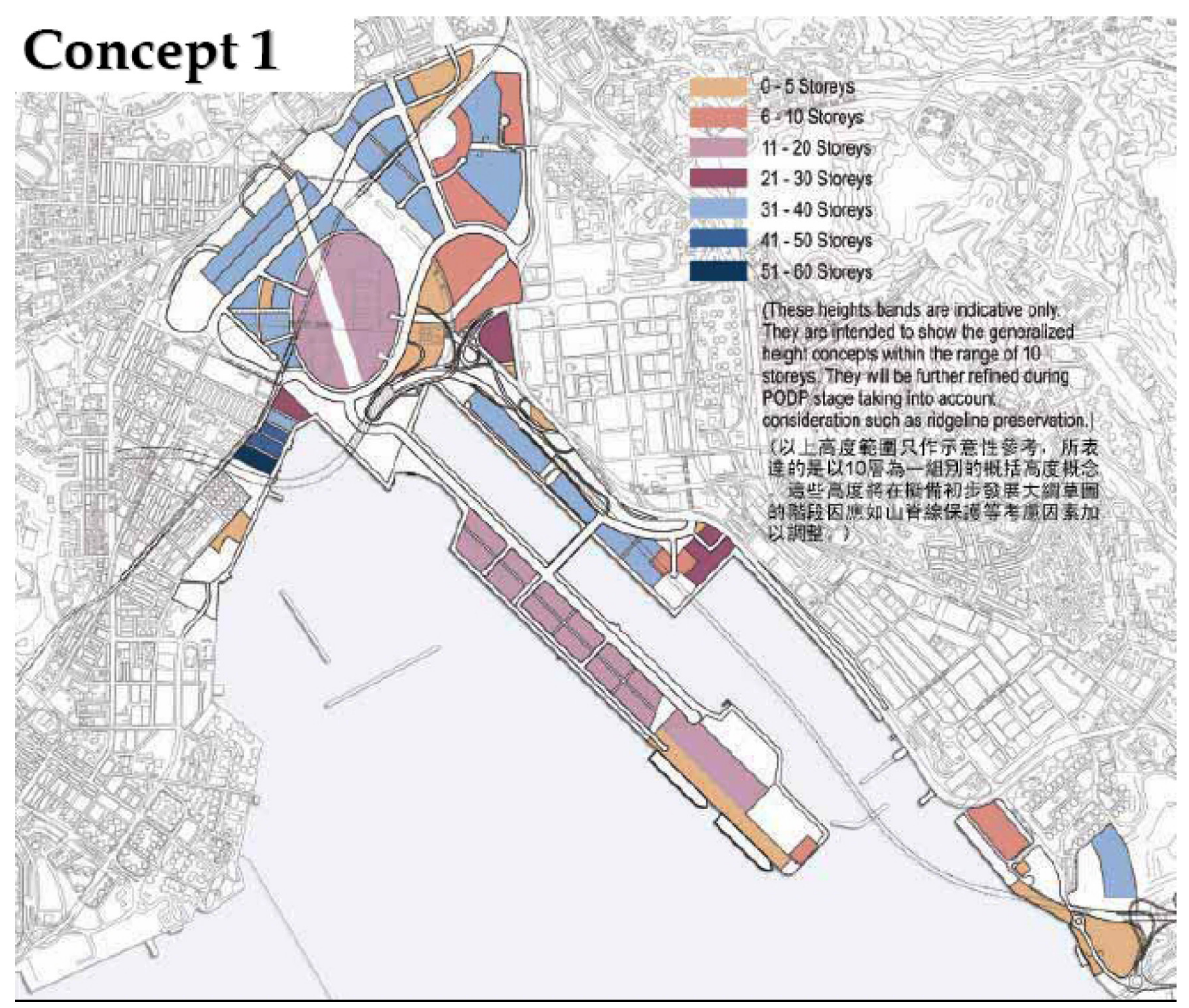

Source: [36].

Fig. (16). Concept 1 - Building height concept.

predominately high quality residential project, a Garden city within the City'. REDA proposed low-rise residential buildings and the concept of a limited mixed use, e.g. some moderate commercial use on the ground floor so as to add vibrancy to the neighbourhood (Fig. 18). Moreover, stepped development could be considered, since it would maximize the enjoyment of the waterfront view [48]. Regarding the population that can be housed in Kai Tak, it is said that if the land currently earmarked for office use is released, a higher overall population might be accommodated in the planning site. In his letter to the Planning Department in response to the Planning Review, Louis Loong stressed again that Kai Tak should be a 'predominately high quality residential project' [48]. REDA believes that Kai Tak presents a unique opportunity to build a high quality 'garden city' within the city. Therefore, a quality residential project is appropriate. REDA suggests private residential housing built on an 'islands' theme which 'maximizes the availability of harbour views with stepped development rising up gradually the further one gets from the harbour front' [48]. The 'islands' theme, according to Loong [48], would create a 'selfflushing mechanism driven by tidal flows'. The maximized water frontage will therefore create amenity and high property values and will make possible any marina uses. This concept is adopted in the Outline Concept Plans issued by the Planning Department as well.

Apart from the government, Swire, and REDA, there are other parties which are in favour of residential development in the planning area. They include HKIP, HKHS, HKGCC and KCDC. These groups want to make use of the prime location of the runway, with its elongated water frontage to build high quality housing. Their suggestions are clearly profit oriented. While the envisioned concept of the whole development is to 'bring people to the harbour' and 'bring 




Source: [36].

Fig. (17). Kai Tak Glamour.

the harbour to the people', having high rise very pricey residential development along the water front is probably not what the general public wants to see.

\section{AGAINST RESIDENTIAL DEVELOPMENT ON THE RUNWAY}

Most people (with the obvious exception of property developers) vetoed the building of quality residential housing on the runway. Societies like The Hong Kong Institutes of Surveyors (HKIS) and the Hong Kong Policy Research Institute Limited (HKPRI) are against a mass development of residential housings in the area. In their opinion, Kai Tak should not be planned into another property-led development resulting in blocks of high-rise buildings in high density [36]. This kind of development will also block the view to the harbour front and the Lion Rock Ridgeline. Also, they argued that there is no prompting demand for housing. A citizen, A. Chan raised his opinion in the consultation forum that the whole runway and waterfront area should only be developed for open space, recreation and tourism so as to fully utilize the waterfront and the magnificent harbour view. It is also one of the planning principles set by the Planning Department that the development should maximize the waterfront area for the enjoyment of the public and to bring the harbour to people, and vice versa, so as to enhance water-man relationship [36]. 


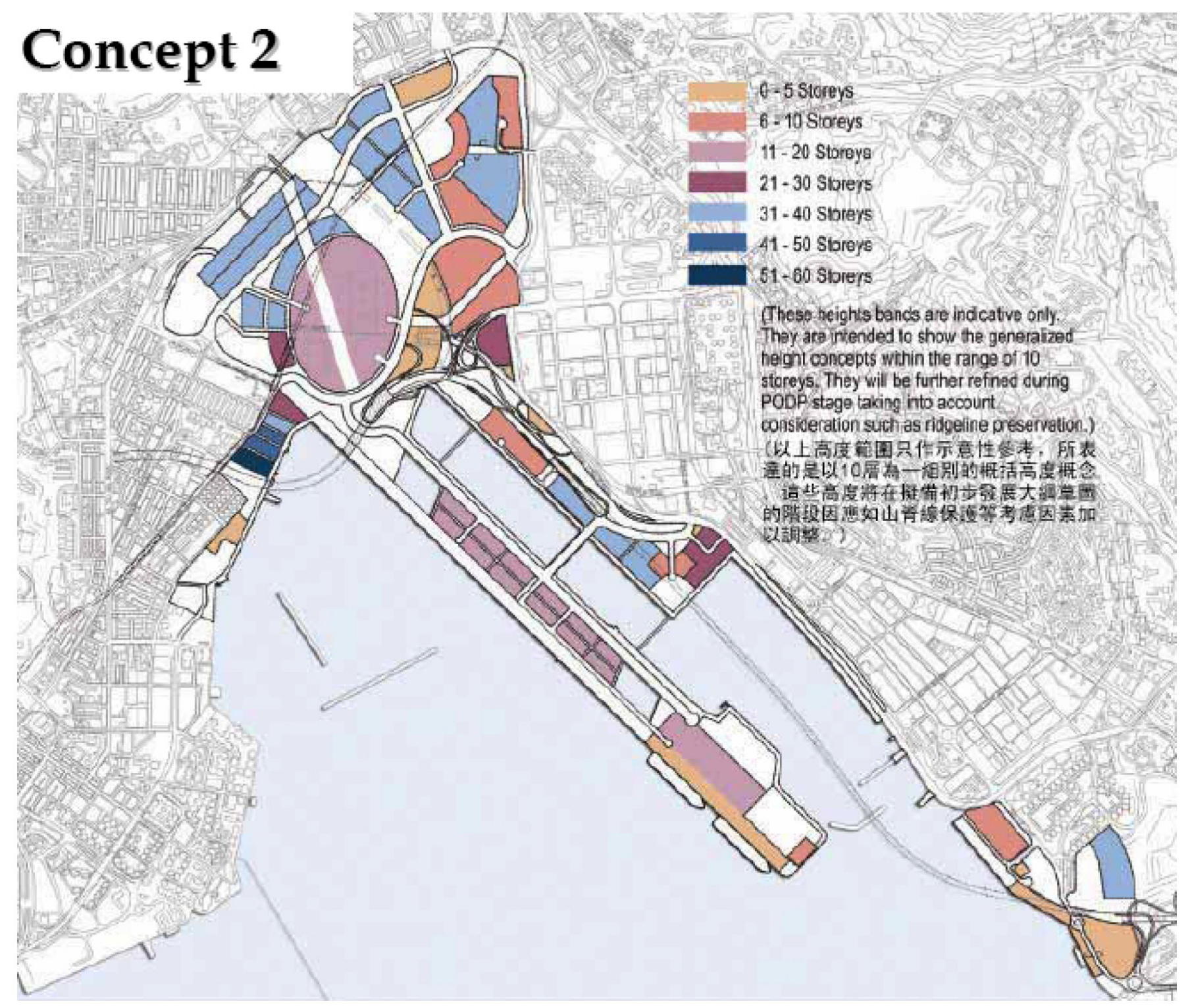

Source: [36].

Fig. (18). Concept 2 - Building height concept.

According to Ho [49], supporter of the SKTC, building a high-density housing community on the runway will not help Hong Kong's economy. The following reasons are given. First of all, it does not open a new market when compared with the aviation industry. Secondly, it cannot attract new investors. Finally, it will not be able to employ as many people as a general aviation airport. The housing proposal will just make Kowloon Peninsula more congested and will kill the aviation culture permanently. It may be true that having high-rise residential buildings along the waterfront will fail to achieve the above principles and that there is no urgent need for residential housings since the prediction indicating an increasing growth rate after the 1996 census was conducted has been proved invalid. The growth rate has been decreasing, and the current population is just 6.5 million, compared to the expected figure of 10 million by 2007 [50]. There is therefore little justification for more residential development. The proposals suggested by property developers mainly aim at profit-making. Fig. (19) shows the expected population to be accommodated in the three Outline Concept Plans issued by the Planning Department.

The latest blueprint issued by the Government in June 2006 proposed residential development to house 86,000 new residents only [42]. Comparing with the previous concept plans, the size of the expected population in the redrawn blueprint has been reduced. However, it is obvious that the government would not give up its residential development plan, although reports had shown there is no prompting demand for housings. Beside the mentioned interest groups, other stakeholders that promoted alternative uses of the runway also objected to the development of residential housing on the runway, since large-scale residential development that occupy the runway would hinder their preferred project. 




Source: [36].

Fig. (19). Expected population and employment figures in the 3 plans.

\section{Third Option: The Cruise Terminal}

The proposal for building a cruise terminal is supported by the majority of the stakeholders. Stakeholders such as BDFHK, HKIS, HKPRI, KCDC, KTCBA and KTPDCG agree that the government should speed up the development of an international cruise terminal at the top of the whole exrunway of Kai Tak to promote tourism and enhance the berthing facilities in Hong Kong for mega cruise ships [36] (Fig. 20). Findings of the latest consultancy studies commissioned by the Hong Kong Tourism Board and the Government showed that there is a great potential for the cruise market to grow significantly in the Asia Pacific region in the near future. Kai Tak Point in South East Kowloon were identified as a suitable location for development of cruise terminal facilities to meet the long term needs of Hong Kong and the location was well received by the cruise industry [36]. As regard to the proposal, concerns were expressed over the environmental impacts of the cruise terminal upon the surrounding areas, such as noise, shipping emissions, and sewage discharge.

Some interest groups are against the construction of a cruise terminal at Kai Tak, including HKDC, REDA, Save Kai Tak Campaign and NTCTA. REDA favours residential development (as mentioned in earlier sections) on the runway, while SKTC would like to reserve the runway for General Aviation [47]. They consider the construction of the cruise terminal at the runway top as rather remote and inconvenient. Some stakeholders proposed alternative locations, such as upgrading the existing Ocean Terminal and providing new facilities at West Kowloon, Hung Hom, near Kowloon Bay or To Kwa Wan, Kau Sai Chau and near Disneyland on Lantau Island [36]. The response to this is that, as set out in the approved Kai Tak Outline Zoning Plan, the runway top has been identified as the preferred site for the development of cruise terminal facilities to meet longterm demand, since it is the only site within the harbour that allows future expansion of berthing facilities [36]. The cruise terminal was included in the Outline Concept Plans 1 and 2 as well (Fig. 20).

In the review conducted by the government, after taking into account all the considerations, such as water depths and room for expansion, Kai Tak is the only available site capable of welcoming large cruise ships. Moreover, it was argued that building the cruise terminal at the runway top will boost tourism development, while complementing the proposed multi-purpose stadium perfectly.

\section{OBJECTION TO THE CONSTRUCTION OF CRUISE TERMINAL BY SKTC}

According to the Save Kai Tak Campaign [47], the construction of the cruise terminal at the runway top ruins Hong Kong's only chance of developing a general aviation industry. The aim of the Save Kai Tak Campaign is to keep the runway for General Aviation and promote Aviation Education in Hong Kong. Apart from displacing local aviation industry development, according to the SKTC, the cruise terminal will also undermine Hong Kong's economic diversification. Furthermore, the opportunity cost is just too 



Source: [36].

Fig. (20). Outline concept plan 1 and 2.

large since it costs way too much to lose the General Aviation industry and economy forever [47]. Since Kai Tak is the only place for a runway for General Aviation, it is suggested that the cruise terminal should be located elsewhere, for example at North Point or at the Whampoa Dockyard, where an established infrastructure already exists. It is also claimed that the proposed cruise terminal would pose severe pollution problems in Kai Tak e.g. noise, air, and water pollution due to its daily operation. It would even upset the ecology since the huge water cooling engines, air conditioners, boilers etc. of a cruise reaching 11 stories below water surface would raise water temperature of the stagnant Kai Tak, which would accelerate the breeding of health-threatening bacteria and the growth of germs. The Campaign argues that the proposed cruise terminal violates planning principles. Furthermore, the Campaign lamented that the blocking of views and ventilation by huge smoke, heat, and noise generating cruises at the planned Runway Park and at open spaces violates the original concept of tourist lookout spot and view corridors, while the planning proposals are supposed to be people-oriented, as stated in the consultation digests [36]. The Campaign claimed that the insistence on constructing the cruise terminal neglected the development of the aviation industry and the survival of the people who work in that field, including many members of the The Hong Kong Aviation Club, and aviators [47]. However, the Planning Department excluded the airfield proposal in the Outline Concept Plan for Stage 2 Public Participation due to numerous factors, including its support for the cruise terminal [36].

\section{Fourth Option: Aviation-Related Developments}

The Save Kai Tak Campaign is eager to save the unused runway of Kai Tak and oppose the construction of Cruise Terminal in the area. The concept plan submitted by the SKTC and other written submissions by individuals proposed an Aviation and Tourism Hub at Kai Tak [47]. The major components include a light aircraft runway within the Aviation Park, a light aviation centre and a museum, with its ancillary facilities. An elevated runway of about $800 \mathrm{~m}$ of length has also been suggested [47]. The SKTC hopes to promote an aviation-related industry by developing some tourist attractions, including an helipad, a monorail and light aircraft aerial sight-seeing flying. The SKTC proposed changing the government's original 'concrete-jungle' plan of Kai Tak into a blueprint that includes [47]: a sizable metropolitan park; a runway park; a huge multi-purpose
Olympic sports stadium complex and sports park; a continuous waterfront promenade and waterfront bazaar, picnic area, and fishing decks; the lowering of housing height to preserve views for the beautiful legendary Lion; rock and Kowloon Hill ridge lines; the preservation of views to Lei Yue Mun; the preservation of the Kai Tak Air Traffic Control Tower; the provision of helicopter facilities at the tip of the runway; an aviation museum, the Kai Tak Heritage Trail and the preservation of the heritage buildings of the flying school and of the Runway Fire Station; a hot air balloon station; an amphitheatre; an aero-modeling grounds; Cycling tracks; a high percentage of green tree and grass lawn areas; facilities for leisure boating and water activities [47].

This proposal was rejected by the government. The Standard reported on December 07, 2005 that the government came under fire after confirming that it had ruled out a proposal to build a runway as part of the Kai Tak redevelopment plan. Anthony Kwan, Assistant Director of Planning, Metro and Urban Renewal at the Planning Department said in a public consultation forum, 'We had already considered the possibility of building a runway during the fist phase public consultation, but after conducing a detailed study; we decided not to include a runway' [51]. This statement infuriated the chairman of Save Kai Tak Campaign, Francis Chin, a retired pilot that had been pushing for a general aviation runway on the old airport site in addition to a planned cruise terminal. Chin told the forum that Hong Kong was not just about cruises or maritime development. 'General aviation is also important, and we need a runway for short-distance flights in the Pearl River Delta region, which Chek Lap Kok airport cannot provide.' [51].

Kwan [51] argued that building of the runway will cause safety issues and noise pollution. After the closure of Kai Tak Airport in 1998, buildings in the area were no longer subject to height restrictions, he explained. As a result, taller structures in the site would make plane navigation dangerous, he said. The Planning Department evaluated the civil airfield proposal and responded that it would impose serious planning and development constraints to Kai Tak as a whole and the surrounding areas. On the basis of Civil Aviation Department's obstacle limitation requirements, the airfield proposal would have two implications to the Kai Tak development. First, on the land side, the obstacle limitation requirements would limit the maximum building height 

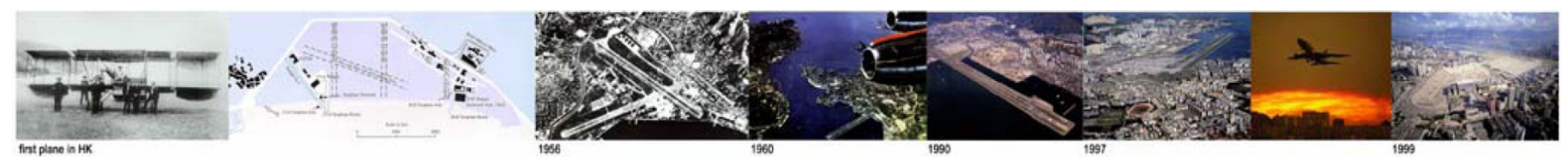

\section{Save Kai Tak Campaign [ AIR-side ]} 㪿 15 ост 2003


kowloon bay

Source: [47].

Fig. (21). The Air-side component of the SKTC proposal.

along the runway area at the North East end of the North apron area, affecting the development potential of the Sun Wong Toi Road area and interfacing with the recently completed redevelopment project therein. Second, on the seaward side, it would restrict vessels heights throughout Kowloon Bay and Victoria Harbour. The proposed cruise terminal would be in conflict with the runway as it is expected to receive cruise liners of 62-65m high [36].

Kwan [51] also claimed that local residents are concerned about potential noise pollution from the planes. However, Chin retorted, 'Aren't you planning to build a heliport at Kai Tak anyway?' [51]. Despite the arguments given by the Planning Department, the SKTC insisted that the runway would not affect the other developments in the area. Chin warned the community to be cautious about a cruise terminal. 'Cruise ships are not like 'pieces if art,' they are like monsters,' he said, refuting a statement made earlier by a cruse industry representative. 'They are noisy and smoky and they will lead to pollution' [51]. The SKTC stated that the proposed small light aircraft runway would not only preserve Hong Kong's aviation heritage and promote her aviation culture, but also lead to a lot more benefits. For instance, it would provide ample employment opportunities, it would help develop Hong Kong's human resources and expertise in aviation especially in pilot training and aviation education, it would provide substantial revenue for the government and it would serve as a regional light aircraft communication hub for the Pan Pearl River Delta/ South China. Furthermore, the Campaign criticized that the support for the proposed cruise terminal is in favour of particular interest groups [47]. According to the SKTC, the Kai Tak Airport could be a good complement to make up for the disabilities and drawback of the Chek Lap Kok Airport for the general aviation economy. The Campaign stressed that a planned preservation in the redevelopment of the Kai Tak Airport would help reduce the budget deficit, generate revenue, provide employment opportunities and facilitate Hong Kong's economic diversification [47].

The SKTC proposed to allocate sufficient areas of the S.E. tip of Kai Tak and 5000 feet of the Runway for the development of a Hong Kong General Aviation Park. The Park would consist of [47]: parkland area (which would include traditional park facilities and venues for model airplane flying, paragliding, go karting, car racing training circuits and other motorized recreational activities); a short runway for light aircraft, helipads, hangers for aircraft storage, hangers for 1 to 2 light aircraft factories/ maintenance workshops, and fire and ambulance depot; the Hong Kong General Aviation Center; sailing and boating arenas along the southern sea front. The SKTC also proposed that The Hong Kong General Aviation Center would be the main multi-purpose complex inside the HK General Aviation Park, which would include facilities and accommodations for different organizations [47]. 


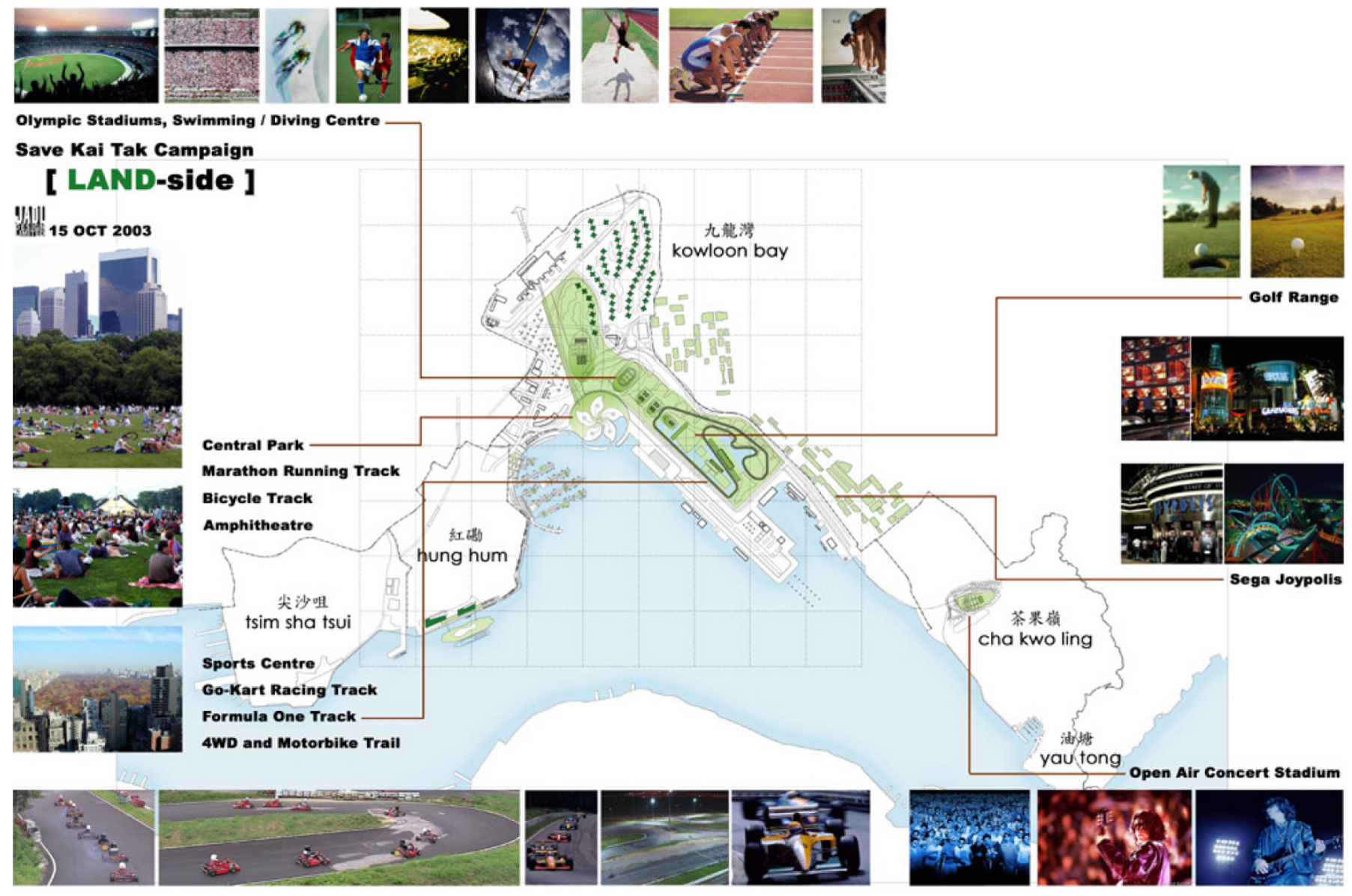

Source: [47].

Fig. (22). Land-side of the plan.

Representatives from the SKTC stated that the cardinal weakness of the existing Kai Tak re-development project is that it is only planned two-dimensionally. To fully and costeffectively exploit the potential of the old Kai Tak Airport for the benefit of Hong Kong and China, an overall land-seaair three-dimensional approach should be adopted [47]. 'The inclusion of the development of the General Aviation Industry in the economy infrastructure will be the HKSAR's new three dimensional land-sea-air tactic in the present 'war' against deflation, budget-deficit, unemployment, diminishing of revenue income revenue outflow and degeneration of industry' [47].

\section{THE THREE DIMENSIONAL LAND-SEA-AIR PROPOSAL}

Hong Kong's former Chief Executive, Tung Chee Hwa, also wished to create a huge city lung theme park with excellent sea view for the redevelopment of Kai Tak and developments concentrating on Sports, Recreation, Culture and heritage, Amusement, Aviation, Navigation and Tourism. Below is the proposed developments planned three-dimensionally [47]. Figs. (21-23) show the air-side, land-side, marine-side components of the SKTC proposal respectively.

At the top of the runway, the SKTC proposed a $5000 \mathrm{ft}$. reserved runway of light aircraft, with the heliport located just next to it (Fig. 21). Other aspects of the plan had been described in earlier sections of this analysis, therefore details will not be repeated.

On the landside, we could find a marathon running track, a central park, a bicycle track and an amphitheatre north of the old airport. Nearer to the runway there would be a golf range, Sega Joypolis, a sports centre, a go-kart racing track and a formula one track (Fig. 22).

Fig. (23) shows that SKTC proposes a historical boat park near to the runway, with featured buildings along the promenade. They also include in the proposal a maritime museum and helium balloon with harbour view. At the top of the runway, there are piazzas, open cafes, seafood restaurants, and retail shops along the waterfront promenade. As for the proposed plans issued by the government, the building of the runway has been ruled out.

Wilson Au Yeung [52], who is Hong Kong's oldest private pilot, criticized the government's way of planning: 'The Hong Kong government doesn't care about general aviation growth. Everything is decided on an economic basis' [52]. Joanlin $\mathrm{Au}$, a pilot for 10 years herself, is 'nostalgic for the old days of Kai Tak'. 'In the past, nobody would leave the club there until midnight. The commercial pilots used to go to the club for a few drinks, the private pilots used to come in for a few drinks. We miss those days' [53]. These observations demonstrate how this group of people view Kai Tak Airport as a precious heritage and 


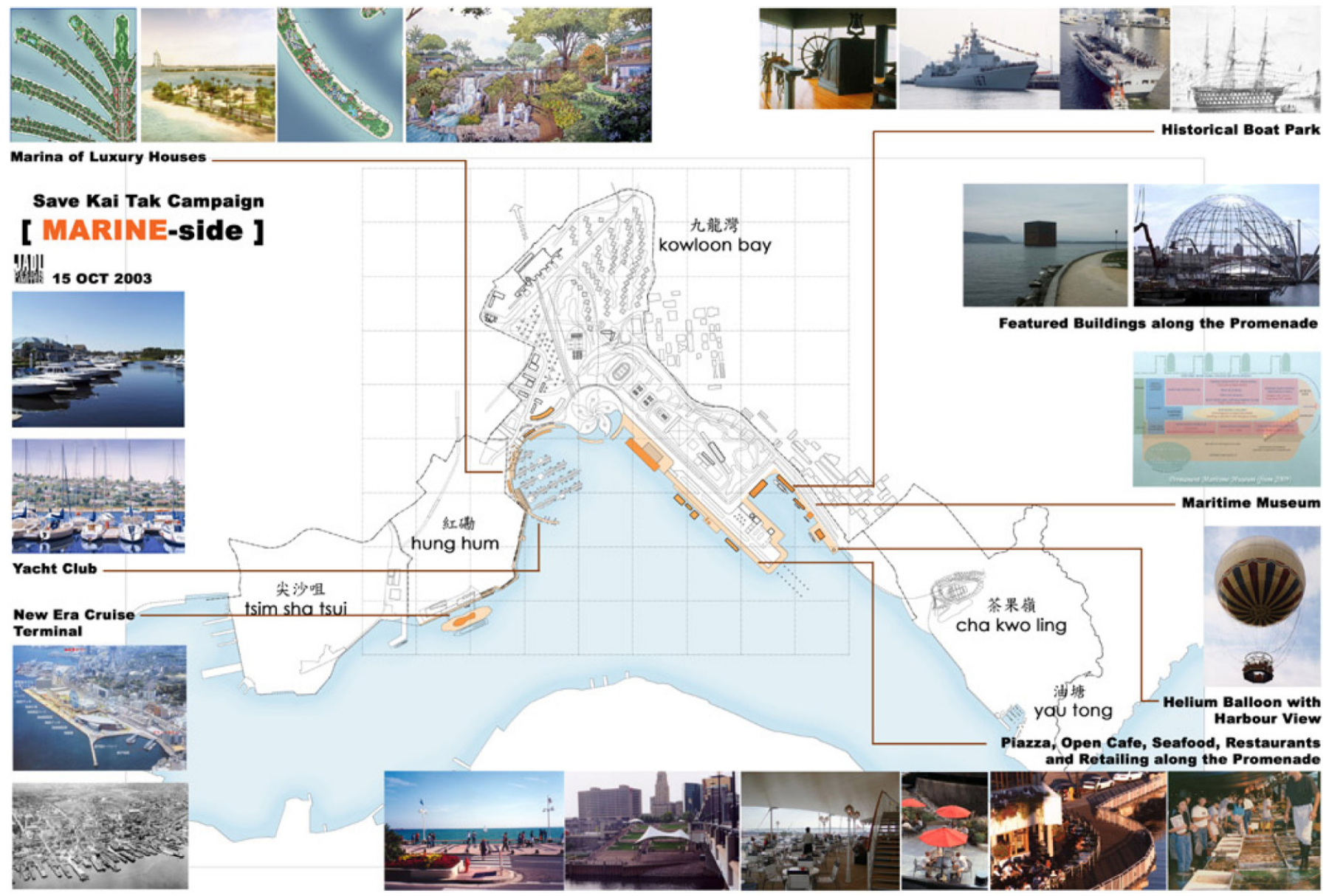

Source: [47].

Fig. (23). Marine-side of the plan.

historical feature of Hong Kong. To them, the recent proposals about residential development, cruise terminal, sports stadium etc. do not help Hong Kong in preserving the remaining bit of local culture, while the majority of the public recognized the contribution of history and memory to building up local characters. The government is in favor of those plans because they emphasize economic growth, even though they ignore the preservation of the local heritage.

\section{DISCUSSION}

From the very beginning of this planning project, it was stated by the Planning Department that the Kai Tak Redevelopment Project is a 'people-oriented' development. The Hong Kong government emphasizes people's rights and liberty, and the significance of public participation in city planning is recognized. The planning history of Kai Tak started as early as in 1991. In 1998, the government had drafted the Kai Tak Outline Zoning Plan and it was published for public exhibition. In 1999, the government conducted a public consultation forum and consultations with Legislative Council Panel on Planning, Lands and Works, professional units, Society for the Protection of the Harbour Limited, Royal Hong Kong Yacht Club, and Real Estate Developers Association on the planning issues and main findings of the draft.
In June 1999, the Town Planning Board considered an Outline Concept Plan, which was forwarded to provide a basis for hearing the objections to the draft Outline Zoning Plans. After this, the Board amended the plans according to comments received. Following this, another public consultation forum with the Legislative Council Panel was conducted. From then on to July 2004, consultation works never ceased. The Kai Tak Planning Review was set up in 2004 and there was then a series of consultation forums and phases of public participation. Outline Concept Plans were published in the Planning Review papers for public participation. After each consultation period, a consultation digest illustrating 'comments received' was published. From these works, we can see how the government tried to involve the community in the planning of Kai Tak. With all those published papers and consultation digests, the government tried to make the planning process as 'transparent' as possible.

The conflicting opinions expressed on the preservation issues are mainly between the preservation of history and the breaking of the runway. Since the breaking of the runway is related to the 'no-reclamation' scenario adopted by the Planning Department, the conflicts between the proreclamation groups and the ones against it were included in the analysis as well. Regarding the proposed future use of the runway, the main proposed components are 1) residential 
development, 2) the construction of a cruise terminal and 3) aviation-related facilities. Each of them is partially in conflict with the other two: the land on the runway is rather limited and since each proposed development is of a large scale and is fighting for the land at the top of the runway, the supporters of one development proposal would veto the other two.

REDA, HKHS and Swire, prominent local property developers, proposed that the runway should be used for quality residential developments. They prefer the development of property 'islands', supposedly because they will maximize waterfront space and eliminate the environmental problems of the Kai Tak Approach Channel. However, the high density and high-rise buildings this approach requires will also block the view to Victoria Harbor and keep people away from the waterfront. It seems likely that the main virtue of these 'islands' is to increase the value of the properties built on them, due to the magnificent harbour view, and maximise the profits of the property developers. Property developers in Hong Kong are not known for their concern for protecting the territory's heritage and environment.

The government clearly shows it favours building a cruise terminal at the top of the runway, as we could see in its Outline Concept Plans. Stakeholders such as BDFHK, HKIS, HKPRI, KCDC, KTCBA and KTPDCG all support the government's decision to develop an international cruise terminal. They view tourism promotion as the most important aim of the development and the old runway should be best utilized to achieve this aim. The Hong Kong Tourism Board and the Government are working for the same goal, namely to expand the cruise market in Hong Kong and turn it into an international hub for cruise industries.

Supporters of aviation-related facilities (with Save Kai Tak Campaign being the largest and most influential group) argue for the importance of heritage preservation and the significance and benefits of developing a General Aviation industry in Hong Kong. In their opinion, residential development and the cruise terminal can be located elsewhere while the old Kai Tak airport site and Runway 13 is the only site and the only opportunity to develop a General Aviation in Hong Kong. Therefore, this group of people is against any of the other options. They strongly promote aviation education in Hong Kong and in their reports and statements stress that the development of General Aviation will help Hong Kong's economic diversification, create employment, and bring benefits to the local citizens and to Hong Kong as a whole.

\section{PLANNING AS A COMPLICATED PROCESS}

Stakeholders participated actively in public consultation forums and submitted their proposals to the planning department, so as to advocate in public their ideas on the future of the runway, and promote their respective interests. The analysis of the planning process, and of the parties involved, show that planning is a complicated, timeconsuming and contradictory process. The idealized representations of the opportunities for communities to participate in the planning processes might appear to be overly optimistic. The government made an effort over the years to launch various programs to get the community involved in the planning process. The general public and different organizations holding different points of view had many chances to express their opinions. However, this involvement of the community has been a time-consuming event, which has delayed the decision on what to do with the runway. Ultimately, whether the wishes of the public will be taken into consideration, is still an open question, because no final decision has yet been made about what to do with the runway. Indeed, since there are three different stakeholders and interest groups with three different plans that exclude each other, the government cannot include all the wishes of the community into its final blueprint, and many members of the community will be unhappy.

We could conclude from the Kai Tak Redevelopment Project that planning is very time-consuming, especially when the site is a valuable strategic location for development. From 1991 to the present, for almost two decades, the government has been considering different options, and can still not settle on a finalized proposal for the old airport site and the piece of land remaining vacant. As mentioned at the beginning of this paper, it is a very difficult task to satisfy every citizen or organization. Complex and adverse planning conditions are constantly faced by the government and the planning units. These complex and adverse conditions include the conflicts and disagreements between the government and the community, and between different interest groups with different aims. As we can observe in this case study, there are many conflicting groups fighting over the runway. They all have a different point of view, their own goals, and they have valid, if contradictory, arguments to promote their ideas and try to convince the general public of the validity of their arguments and the government to approve their proposals.

\section{CONCLUSIONS}

Similarly to the protests and demonstrations that were launched when the Central Star Ferry Pier and the Clock Tower were demolished, the campaign launched by the Save Kai Tak Campaign shows the recognition of the importance of heritage preservation for local citizen. It also implies that people believe that heritage and history are being neglected by the local government. These protests and gatherings were made to happen because the government is acting contrary to the wishes of the public. While the demonstrators were gathering to protecting the Clock Tower, the Save Kai Tak Campaign was trying its best to Save the old Kai Tak Airport. If the government action is perceived to be 'contrary' to the wishes of the people, what will happen? Will more radical protests and demonstrations take place? In order to prevent these from happening, should the government recognize the need of the community? Or has the government set in motion the expectation for a more participatory land use planning in Hong Kong, by attempting to include public opinion in the Kai Tak Redevelopment Project? Do people now expect the government to incorporate ideas collected in consultation forums into their planning proposals? Only when the finalized plan for Kai Tak is published, will they be able to tell whether the consultations were sincere attempts to grant planning rights to people, or merely public relation exercises to ease public discontent. 


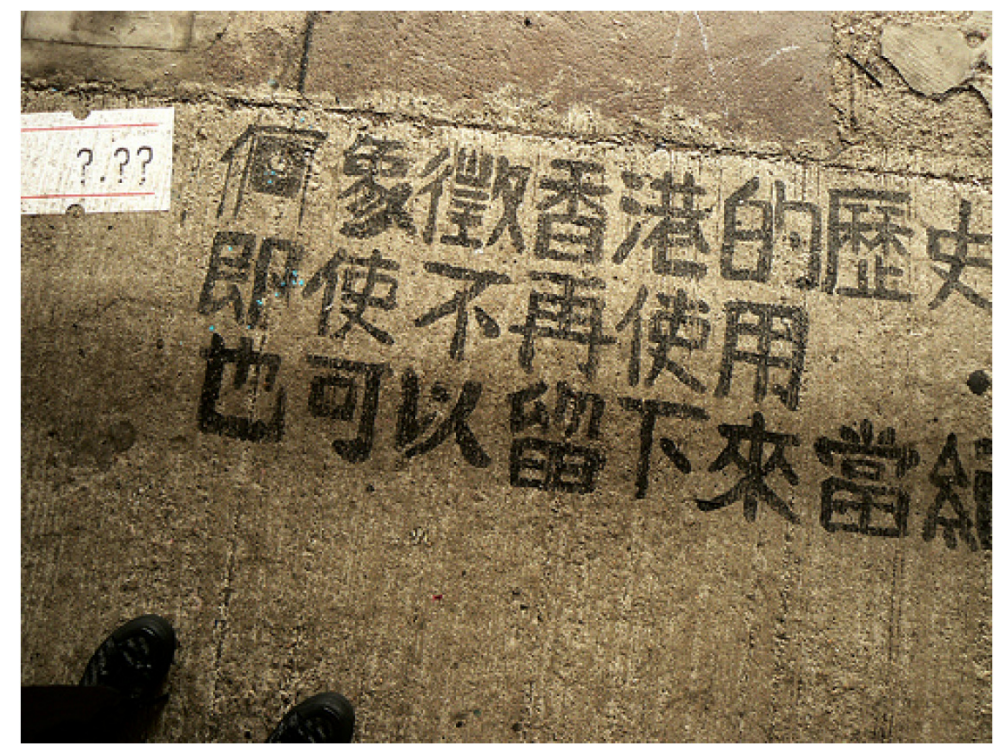

Source: [54].

Fig. (24). Writing protesting the demolition of the Clock Tower. Picture taken 16.12.2006.

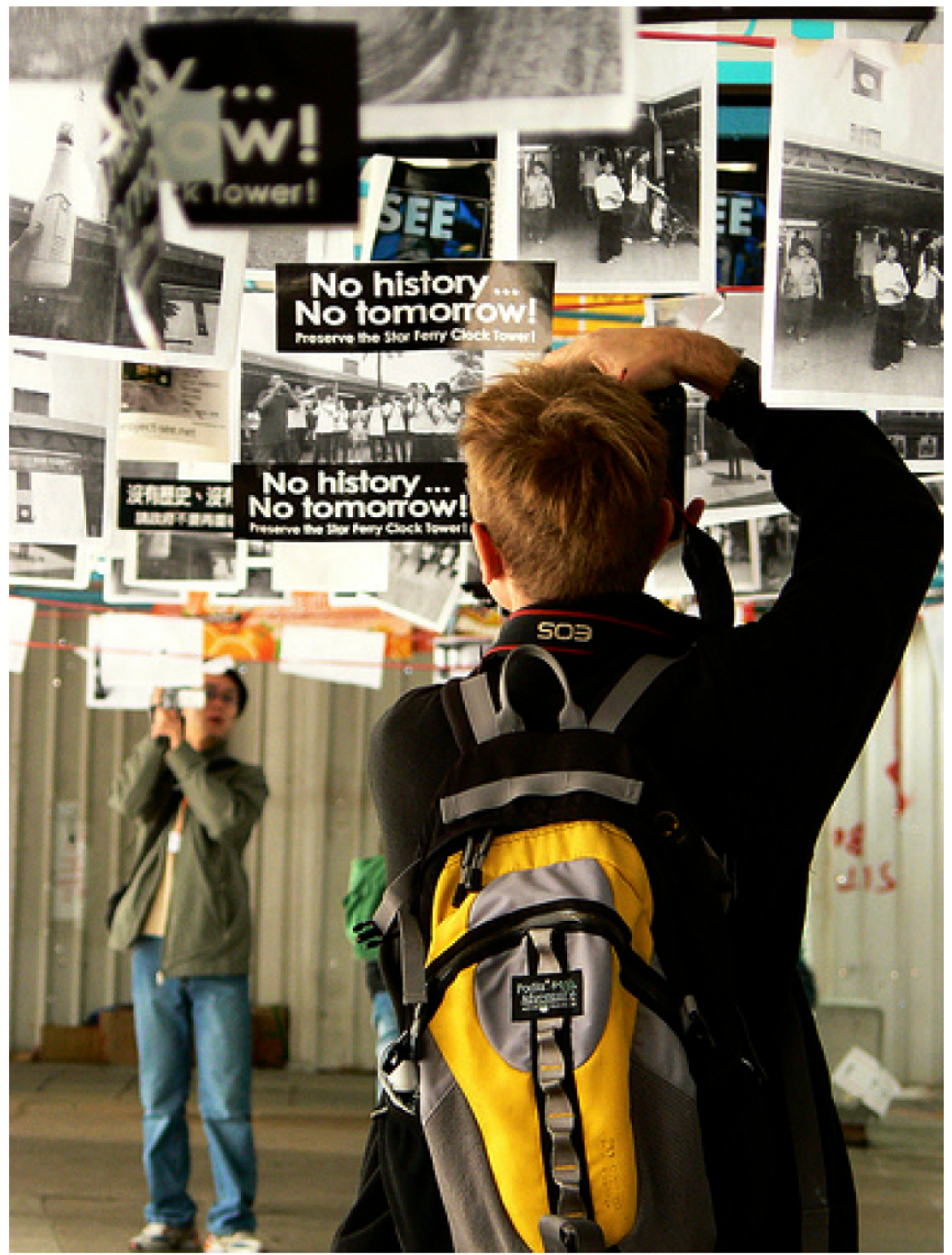

Source: [54].

Fig. (25). Posters hang in protest of the demolition of the Clock Tower. Picture taken 16.12.2006. 
Fig. (24) was taken in the period the Clock Tower was demolished. Written on the ground is that 'The Clock Tower symbolizes the history and memories of Hong Kong, even if it is not going to be used again, we can still keep it'.

Fig. (25) shows hundreds of little posters hung up protesting against the destruction of local history. The posters say that 'No history, No tomorrow!'

What is the message behind these slogans? Kai Tak Airport is certainly an important asset to Hong Kong. It symbolizes its past glory and development. Its retention would add to Hong Kong's uniqueness and local character, as well as its historical, cultural and architectural history. Hong Kong has already sacrificed most of its local heritage to the lure of economic development, and has been characterised as a place with no historical anchor. Should Hong Kong people learn from their past mistakes and stop destroying their history and memory? Undoubtedly, the Kai Tak runway serves as a unique and valuable perspective of the personal living space of the people living in Hong Kong and helps enhance the richness and diversity of their lives as well. By keeping it, they can retain both the knowledge and the memories it evokes.

\section{REFERENCES}

[1] Ho P. Heritage preservation vital. 2006 [Retrieved 1st March 2007]. Available from: http://www.news.gov.hk/en/category/onthe record $/ 060915 / \mathrm{html} / 060915 \mathrm{en} 11001 . \mathrm{htm}$

[2] Veal AJ. Research methods for leisure and tourism. Harlow: Longman 1992.

[3] Chadwick GA. Systems view of planning. Oxford: Pergamon Press 1971.

[4] Hall P. Urban and Regional Planning; $2^{\text {nd }}$ ed. Harmondsworth: Penguin 1982.

[5] Hall CM, Jenkins J. Tourism and public policy. London: Routledge 1995.

[6] Hall CM. Introduction to tourism in Australia: impacts, planning and development; $2^{\text {nd }}$ ed. South Melbourne: Longman Australia 1995.

[7] Logan J, Molotch, H. Urban fortunes: the political economy of space. Berkeley: University of California Press 1987.

[8] Lin GCS. The growth and structural change of Chinese cities: a contextual and geographical analysis. Cities 2002; 19(5): 299-316.

[9] Murphy P. Tourism: a community approach. New York and London: Methuen 1985.

[10] Getz D. Tourism planning and research: traditions, models and futures; Paper presented at The Australian Travel Research Workshop, Bunbury, Western Australia, 5-6 November, 1987.

[11] Gunn CA. Tourism planning; $3^{\text {rd }}$ ed. Washington: Taylor \& Fancis 1994.

[12] Inskeep E. Tourism planning: an integrated and sustainable development approach. New York: Van Nostrand Reinhold 1991.

[13] Tyler D, Guerrier Y, Robertson M. Managing tourism in cities policy, process and practice. New York: J. Wiley 1998.

[14] Punter J. Urban design in central Sydney 1945-2002: Laissez Faire and discretionary traditions in the accidental city: School of City and Regional Planning, UK 2004.

[15] Harvey D. Between space and time: reflections on the geographical imagination. Ann Assoc Am Geogr 1990; 80: 418-34.

[16] Mommaas H, van der Poel H. Changes in economy, politics and lifestyles: an essay on the restructuring of urban leisure; In: Bramham P, Henry I, Mommaas H, van der Poel H, Eds, Leisure and Urban Processes: Critical Studies of Leisure Policy in Western European Cities. London: Routledge 1989; pp. 254-76.

[17] Hall CM. Introduction to tourism development, dimensions and issues; $3^{\text {rd }}$ ed. South Melbourne: Addison-Wesley Longman 1998.

[18] Sairinen R, Kumpulainen S. Assessing social impacts in urban waterfront regeneration. Environ Impact Assessment Rev 2006.

[19] Breen A, Rigby D. The new waterfront. A worldwide urban success story. Singapore: Mcgraw-Hill 1996.

[20] Feldman M. Urban waterfront regeneration in the Baltic States: the case of Tallinn, North European and Baltic Sea integration. Berlin: The NEBI Yearbook 1999, Nordregio/Springer 1999; pp. 121-33. Abstract-EconLit.

[21] Roberts P. Urban Regeneration. London: Sage 2000; pp. 9-36.

[22] Malone P. City, capital and water. New York: Routledge 1996.

[23] Harvey D. Transformation to entrepreneurial urban governance in late capitalism. Geogr Ann 1989; pp. 3-21.

[24] Jenks M. The compact city: a sustainable urban form? London: E\&FN Spon 1996.

[25] Leisure \& Cultural Services Department. Antiquities and Monuments Office webpage. 2007; Available from: http://www.amo.gov.hk/en/about.php [Retrieved 1 March].

[26] Urban Renewal Authority. The Urban Renewal Website. 2007 [retrieved $1 \mathrm{March}$ ] from: http://www.ura.org.hk/html/c204000e1 e.html

[27] Urban Renewal Authority. Redevelopment, 11 July 2005; [retrieved 1 March 2007]. Available from: http://www.ura.org.hk/ $\mathrm{html} / \mathrm{c} 400000 \mathrm{e} 1 \mathrm{e} . \mathrm{html}$

[28] Urban Renewal Authority. Rehabilitation, 16 April 2009; Available from: http://www.ura.org.hk/html/c500000e1e.html [retrieved 1 July 2009].

[29] Urban Renewal Authority. Revitalisation, 27 May 2005; Available from: http://www.ura.org.hk/html/c600000ele.html [retrieved 1 July 2009]

[30] Urban Renewal Authority. Preservation, 13 July 2005. Available from: http://www.ura.org.hk/html/c700000e1e.html [retrieved 1 March 2007]

[31] Planning Department. 2005; Public Consultation Digest (2). Available from: http://www.pland.gov. $\mathrm{hk} / \mathrm{p}$ _study/prog_s/sek_09/website_chib5_eng/english/Stage $\% 202 \%$ 20Public\%20Participation\%20Digest_Eng.pdf [retrieved 1 March 2007].

[32] Kai Tak International Airport. 1998; Kai Tak Airport website, Available from: http://www.gov.hk/cad/english/kaitak.html [retrieved 1 march]

[33] Planning Department. 2004; Public Consultation Report (1), Available from: http://www.pland.gov.hk/p_study/prog_s/sek 09/ website_chib5_eng/english/Stage_1_PP_report_Final_ENG.pdf [retrieved 1March 2007]

[34] Wikipedia. 2007; Kai Tak Airport. [Retrieved March 1st 2007], Available from: http://en.wikipedia.org/wiki/Kai_Tak

[35] Jetphotos.net. 2007; jetphotos.net Available from: http://web2. jetphotos.net/ [Retrieved 1 March 2007],

[36] Planning Department. 2005; Public Consultation Report (2), Available from: http://www.pland.gov.hk/p_study/prog_s/sek_09/ website_chib5_eng/english/Stage2_PP_Report_Eng.pdf [retrieved 1March 2007],

[37] Burdge R, Vanclay F. The practice and future of social impact assessment. In: Burdge R, Edt. A conceptual approach to social impact assessment; Middleton, WI: Social Ecology Press 1998; pp. 265-84.

[38] Creighton JL, Chalmers JA, Branch K. Integrating planning and assessment through public involvement. In: Daneke G, Garcia M, Priscoli JD, Edts., Public involvement and social impact assessment. Boulder, CO: Westview Press 1983; pp. 177-184.

[39] Court of Final Appeal. Protection of the Harbour Ordinance. 2004.

[40] Planning Department. 2004; Public Consultation Digest (1), [Retrieved 1March 2007], Available from: http://www.pland.gov. hk/p_study/prog_s/sek_09/website_chib5_eng/english/Consult_Dig est_1.pdf

[41] Kai Tak Planning Review website, 2004; [retrieved 1 March 2007], Available from: http $\% 3 \mathrm{~A} / / \mathrm{www}$.pland.gov.hk/p_study/prog_s/ sek_09/website_chib5_eng/english/index.html

[42] The Standard. 2006; Kai Tak Blueprint Redrawn, dated 18 October 2006.

[43] Arup-Scott Wilson Joint Venture. 2002; Kai Tak Approach Channel Reclamtion. [retrieved 1 March 2007], Available from: http://www.epd.gov.hk/eia/register/profile/latest/esb098.pdf

[44] Kai Tak Planning Review. 2006; [Retrieved 1 March 2007], Available from: http://www.chamber.org.hk/streaming/ppt/2006/ HBF_14022006.pdf

[45] Swire Group. 2005; A Sustainable Concept Masterplan for Kai Tak, [retrieved March 2007], Available from: http://www.swire properties.com/kaitak/background/long_term_value_creation.htm 
[46] The Business and Professionals Federation of Hong Kong. 2005; The Business and Professionals Federation of Hong Kong website, [retrieved 1 March 2007], Available from: http://www.bpf.org.hk/

[47] Save Kai Tak Campaign. 2005; Save Kai Tak Campaign Website, [retrieved 1 March 2007]. Available from: http://www.save kaitak123.netfirms.com/new_page_1.htm

[48] Loong L. Letter to Panel on Planning, Lands and Works. 2006.

[49] Ho CC. Hong Kong Kai Tak Airport Business Development Proposal; 2003, [retrieved 1 April 2007], Available from: http://www.savekaitak123.netfirms.com/new_page_1.htm
[50] Economist Intelligence Unit. 2005; Factsheet. [Retrieved February 6, 2006]. Available from: http://www.economist.com/countries/ HongKong/profile.cfm?folder=Profile-FactSheet

[51] The Standard. 2005; Shelving of Kai Tak runway draws fire. dated 07 December 2005.

[52] Wilson Au Yeung. 2003; Soar Spot, SCMP. dated 11 December 2003.

[53] South China Morning Post. 2003; Soar Spot, SCMP. dated 11 December 2003

[54] http://laihiu.nicesoda.com 2007; [Retrieved 8 April 2007] Available from: http://aihiu.nicesoda.com/

Received: March 31, 2009

(C) Delang and Ng; Licensee Bentham Open.

This is an open access article licensed under the terms of the Creative Commons Attribution Non-Commercial License (http://creativecommons.org/licenses/by$\mathrm{nc} / 3.0 /$ ) which permits unrestricted, non-commercial use, distribution and reproduction in any medium, provided the work is properly cited. 